\title{
Expression of phenylalanine ammonia lyases in Synechocystis sp. PCC 6803 and subsequent improvements of sustainable production of phenylpropanoids
}

\author{
Kateryna Kukil and Pia Lindberg ${ }^{*}$ (i)
}

\begin{abstract}
Background: Phenylpropanoids represent a diverse class of industrially important secondary metabolites, synthesized in plants from phenylalanine and tyrosine. Cyanobacteria have a great potential for sustainable production of phenylpropanoids directly from $\mathrm{CO}_{2}$, due to their photosynthetic lifestyle with a fast growth compared to plants and the ease of generating genetically engineered strains. This study focuses on photosynthetic production of the starting compounds of the phenylpropanoid pathway, trans-cinnamic acid and p-coumaric acid, in the unicellular cyanobacterium Synechocystis sp. PCC 6803 (Synechocystis).
\end{abstract}

Results: A selected set of phenylalanine ammonia lyase (PAL) enzymes from different organisms was overexpressed in Synechocystis, and the productivities of the resulting strains compared. To further improve the titer of target compounds, we evaluated the use of stronger expression cassettes for increasing PAL protein levels, as well as knock-out of the laccase gene s/r1573, as this was previously reported to prevent degradation of the target compounds in the cell. Finally, to investigate the effect of growth conditions on the production of trans-cinnamic and $p$-coumaric acids from Synechocystis, cultivation conditions promoting rapid, high density growth were tested. Comparing the different PALs, the highest specific titer was achieved for the strain AtC, expressing PAL from Arabidopsis thaliana. A subsequent increase of protein level did not improve the productivity. Production of target compounds in strains where the s/r1573 laccase had been knocked out was found to be lower compared to strains with wild type background, and the $\Delta$ s/r1573 strains exhibited a strong phenotype of slower growth rate and lower pigment content. Application of a high-density cultivation system for the growth of production strains allowed reaching the highest total titers of transcinnamic and $p$-coumaric acids reported so far, at around 0.8 and $0.4 \mathrm{~g} \mathrm{~L}^{-1}$, respectively, after 4 days.

Conclusions: Production of trans-cinnamic acid, unlike that of $p$-coumaric acid, is not limited by the protein level of heterologously expressed PAL in Synechocystis. High density cultivation led to higher titres of both products, while knocking out s/r1573 did not have a positive effect on production. This work contributes to capability of exploiting the primary metabolism of cyanobacteria for sustainable production of plant phenylpropanoids.

Keywords: Synechocystis sp. PCC 6803, Phenylalanine ammonia lyase, trans-cinnamic acid, p-coumaric acid, Shikimate pathway, Laccase, High-density cultivation

*Correspondence: pia.lindberg@kemi.uu.se

Microbial Chemistry, Department of Chemistry - Ångström, Uppsala

University, Box 523, SE 75120 Uppsala, Sweden

\section{Background}

Aromatic amino acids (AAA) and their derivatives phenylpropanoids, represent a large group of plant secondary metabolites that includes flavonoids, coumarins, original author(s) and the source, provide a link to the Creative Commons licence, and indicate if changes were made. The images or other third party material in this article are included in the article's Creative Commons licence, unless indicated otherwise in a credit line to the material. If material is not included in the article's Creative Commons licence and your intended use is not permitted by statutory regulation or exceeds the permitted use, you will need to obtain permission directly from the copyright holder. To view a copy of this licence, visit http://creativecommons.org/licenses/by/4.0/. The Creative Commons Public Domain Dedication waiver (http://creativeco mmons.org/publicdomain/zero/1.0/) applies to the data made available in this article, unless otherwise stated in a credit line to the data. 
stilbensenes, lignols, and catechin. These compounds are widely applicable as food additives, fragrances, cosmetics, nutraceuticals, and for production of antibacterial, antitumor, antiviral drugs and other pharmaceuticals [1-4]. The huge market demand for plant bioactive secondary metabolites is at present mostly fulfilled through demanding and inefficient extraction from plant tissues, or through chemical synthesis based on fossil resources, which in many cases is difficult to achieve due to the structural complexity of the desired metabolites and often results in mixtures of isomers. Microbial synthesis of such compounds presents an attractive alternative. Engineered microorganisms can be designed to generate more of a desired product per cell than what can be achieved in plants, while at the same time, the biosynthetic pathways in the host microorganisms can be very specific to generate only one product, and the production will be scalable and more sustainable [5-7].

Engineered cyanobacteria exhibit a great potential for sustainable production of plant phenylpropanoids by direct conversion of $\mathrm{CO}_{2}$. Just as other autotrophs, cyanobacteria possess a pathway for de novo biosynthesis of AAA phenylalanine (Phe), tyrosine (Tyr) and tryptophan (Trp) from the common precursor chorismate through the shikimate pathway (Fig. 1) (Kyoto Encyclopedia of Genes and Genomes (KEGG); https:// www.genome.jp/kegg/). The pathway starts from the condensation of erythrose-4-phosphate (E4P) and phosphoenolpyruvate (PEP), derived from $\mathrm{CO}_{2}$ fixation in central carbon metabolism, to form the first compound in the shikimate pathway, 3-deoxy-D-arabinoheptulosonate 7-phosphate synthase (DAHP). This first step is catalyzed by the enzyme DAHP synthase. This enzyme in microorganisms, supposedly including cyanobacteria, is subjected to tight regulation by feedback inhibition by the products of the pathway $[8,9]$. Through six consecutive reactions, DAHP undergoes cyclisation to form chorismate, which in cyanobacteria is a common substrate for the three AAA, plastoquinone, and folic acid [10-12]. From chorismate, by one additional step, Phe can be non-oxidatively deaminated to form transcinnamic acid $(t C A)$ by the action of an enzyme called phenylalanine ammonia lyase (PAL, EC 4.3.1.24). The PAL enzymatic reaction plays a key role in synthesis of phenylpropanoids, linking secondary metabolites synthesis with primary metabolism. In plants, $t \mathrm{CA}$ can be further converted to $p$-coumaric acid ( $p \mathrm{Cou}$, or otherwise named hydroxycinnamic acid) by membrane bound cinnamate-4-hydroxylase $(\mathrm{C} 4 \mathrm{H})$ [13]. Alternatively to $\mathrm{C} 4 \mathrm{H}$, the enzyme tyrosine ammonia lyase (TAL, EC 4.3.1.25) which was discovered in bacteria, catalyzes a non-oxidative deamination to form $p$ Cou directly from Tyr. PAL and TAL are widely spread in nature, however in bacteria

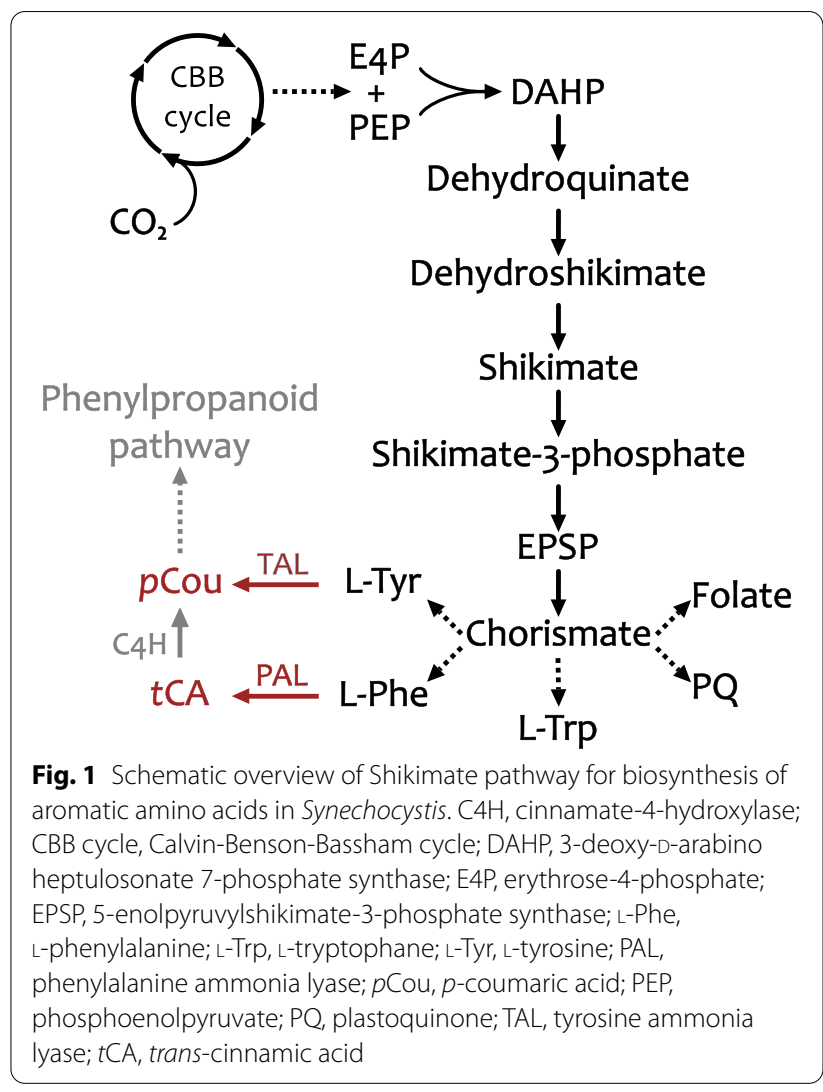

their role is connected to synthesis of the chromophore of photoactive yellow protein and antibiotics [14-16] rather than synthesis of flavonoids and coumarins as in plants [17]. PAL was also discovered in filamentous cyanobacteria, but not in unicellular strains, and yet its role in metabolism in these organisms has not been elucidated [18].

A distinct class of PALs is represented by bifunctional enzymes that can utilize both Phe and Tyr with close to similar efficiencies $[19,20]$. The ability of an enzyme to use both substrates led to investigation of a possible region in the protein amino acid sequence that might be responsible for substrate preference. The discovery of such a region, called substrate selectivity switch, showed that a single amino acid substitution can dictate whether an enzyme will use Phe or Tyr as a substrate [21]. PAL and TAL together with histidine ammonia lyase (HAL, EC:4.3.1.3) belong to the ammonia lyase family of proteins. All three of them share the common characteristic of a modified prosthetic group, 3,5-dihydro-5-methylidine-4H-imidazol-4-one (MIO), a unique prosthetic group which is formed autocatalytically from a highly conserved Ala-Ser-Gly tripeptide sequence (ASG motif) [22]. Crystal structure studies revealed that eukaryotic PALs differ from prokaryotic being $\sim 20 \mathrm{kDa}$ larger 
by the presence of $\mathrm{N}$-terminus extension and an additional insertion domain. This additional domain forms an arch-like structure over the active site, that proposedly is acting as a shielding domain which restricts substrate entry to the active site, however its exact role is unknown $[18,23,24]$.

Cyanobacterial AAA biosynthesis is less studied than that in plants, yeasts and some other bacterial hosts like Escherichia coli, presenting a challenge for engineering. Nevertheless, the photosynthetic nature of cyanobacteria and their faster growth rate than that of plants make them good candidates for sustainable production of AAA and phenylpropanoids, and a few reports have described cyanobacteria engineered for this purpose. To date, cyanobacterial production of $t \mathrm{CA}$, caffeic acid [25], $p \mathrm{Cou}$ [26-28], and phenylethanol [29] has been demonstrated. The common strategies implemented to improve the productivity in cyanobacteria were enhancing the carbon flux into shikimate pathway by reliving the feedback inhibition of key steps in the pathway, such as overexpression of feedback-resistant DAHP synthase and feedback-resistant chorismate mutase/prephenate dehydratase from E. coli. Xue and coworkers [26] discovered a putative laccase in Synechocystis sp. PCC 6803 encoded by $\operatorname{slr} 1573$, and deletion of this gene led to increased $p$ Cou titers, presumably due to involvement of the laccase in oxidation of phenolic compounds. Another strategy for productivity boost consisted in knocking-out of a competing pathway: deletion of arogenate dehydrogenase encoded by tyrA from the terminal branch of Tyr biosynthesis led to the enhancement of the two-step $p$ Cou biosynthesis pathway via Phe and $t \mathrm{CA}$. However, it is not clear how the cells are able to survive a knockout of this supposed essential gene, unless other reactions leading to Tyr synthesis exist in cyanobacteria [30].

In this study we comparatively express and test several PALs originating from different organisms for the production of $t \mathrm{CA}$ in the model cyanobacterium Synechocystis sp. PCC 6803 (hereafter Synechocystis), in strains with and without the $\operatorname{slr} 1573$ laccase gene. We also test engineered strains under more optimal growth conditions; recently, a high-density cultivation system exhibited a great potential of reaching high cumulative titer of desired product in short period of time [31-33]. The reaction performed by PAL is of industrial interest since it opens a gateway to generating a myriad of highly valuable secondary plant metabolites, non-native to cyanobacteria.

\section{Results and discussion Comparative production of $t C A$}

In this study we aimed to use several PAL enzymes in order to test and select the one most favorable for $t \mathrm{CA}$ production in Synechocystis. For this, we searched the literature for available kinetic data on purified PAL proteins, and from available data choose a set of genes with different origins and characteristics. Selected candidates for pal genes were from two plant species, Petroselinum crispum (Pc) [34] and Arabidopsis thaliana (At) [35], and two filamentous cyanobacteria Nostoc punctiforme $(N p)$, Anabaena variabilis (Av) [18]. For these PAL candidates, in vitro studies on their biochemical properties were available in the literature. In addition to these already purified and described PAL enzymes, we also decided to include a fifth PAL candidate, based on the PAL evolutionary study of Hemmati [36]. In that study, a phylogenic tree generated for 369 aligned amino acid sequences of PAL showed that several PAL enzymes do not cluster together. As suggested by the author, those PAL enzymes are probably encoded by pal isozymes with unique functional genes. Among several options from such unclustered PAL candidates, our choice fell to the bacterial PAL from Treponema socranskii subsp. paredis ATCC $35535(T s)$. The choice of this PAL candidate was partially based on the unusual amino acids residues at the positions 86 and 87 . These residues, which correspond to the substrate specificity [21], are phenylalanine and histidine in the case of Ts PAL instead of the more canonical pair phenylalanine-leucine for PAL or histidine-leucine for TAL properties.

The five genes encoding different PAL candidates were cloned in two types of expression vectors (Fig. 2): pEEK [37], and its derivative pEEKN, and successfully

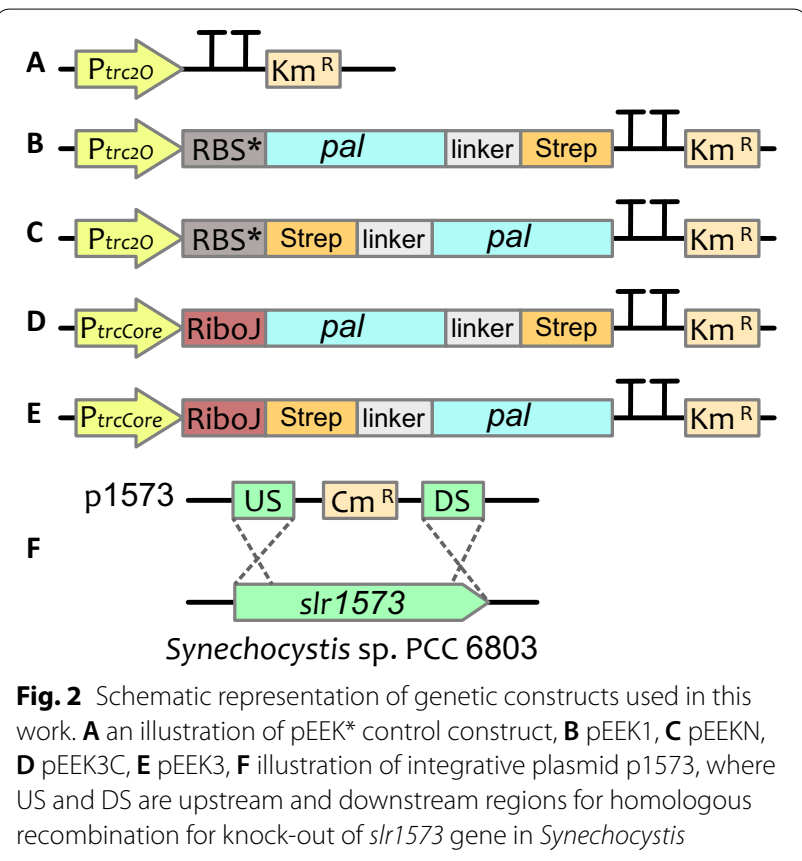


conjugated into Synechocystis (see Table 1 for a list of plasmid backbones used and strains created in this study). In this approach, each pal gene is expressed in two versions, with either an $\mathrm{N}$ - or a $\mathrm{C}$-terminal
Strep-tag in order to evaluate the protein expression and production of $t \mathrm{CA}$ in Synechocystis. An empty vector control strain was obtained by conjugating

Table 1 List of plasmid backbones and Synechocystis strains used in this study

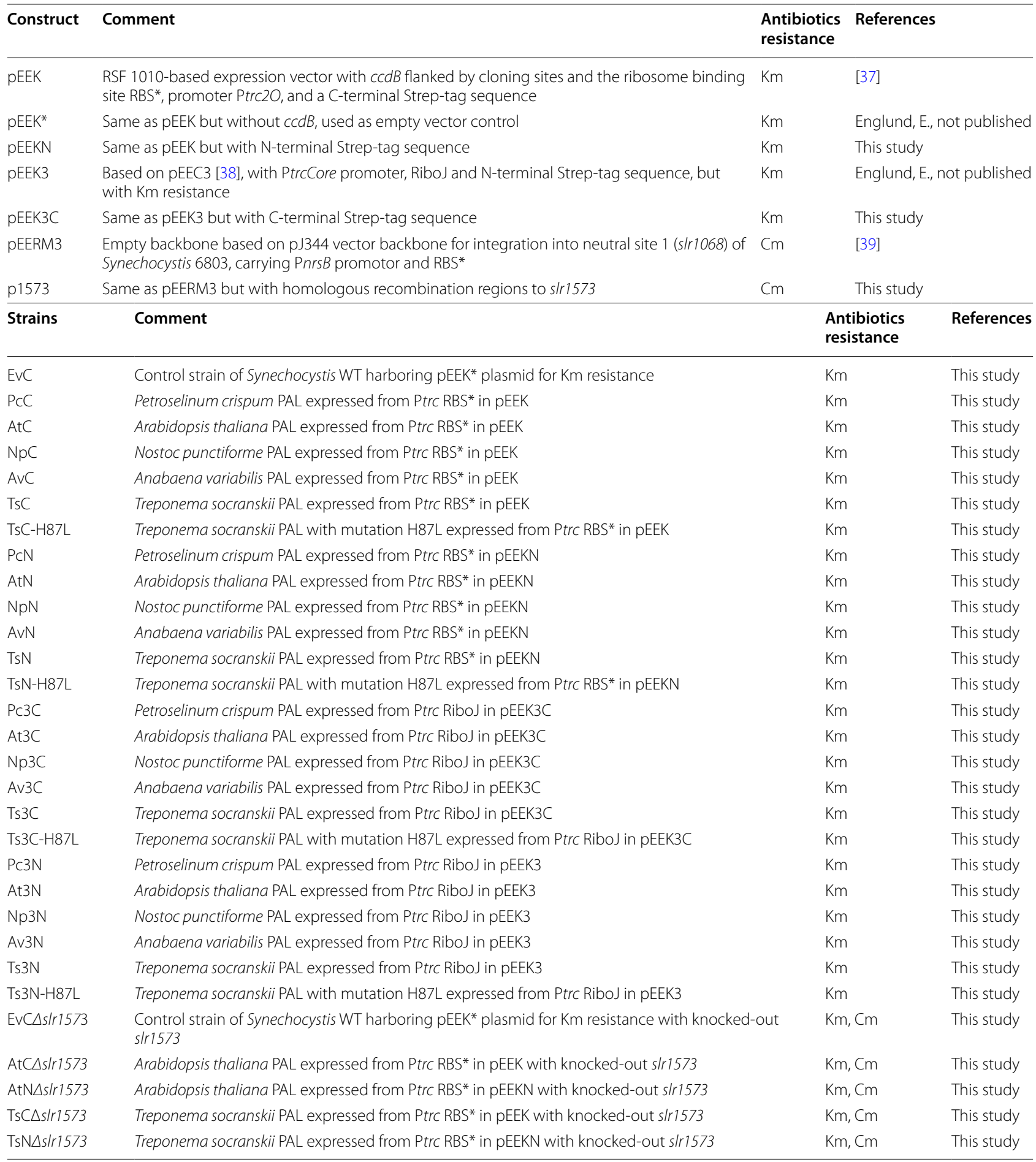


Synechocystis with the pEEK* plasmid, which only contains the $\mathrm{Km}$ antibiotic resistance.

Interestingly, when initially all of the pal expression constructs were tested in $E$. coli for the corresponding $t \mathrm{CA}$ or $p$ Cou presence in the culture medium, it was revealed that Ts pal encodes a Tyrosine ammonia lyase, producing $p$ Cou from Tyr (see Additional file 1: Fig. S1). To explore a possibility that by switching the histidine at position 87 to leucine, the substrate specificity would change from Tyr to Phe, we performed site directed mutagenesis on the Ts tal sequence. As a result, it was found that the mutation $T s-\mathrm{H} 87 \mathrm{~L}$ successfully altered the enzyme selectivity towards phenylalanine, as no $p$ Cou was accumulating in the medium (Additional file 1: Fig. S1). The Ts-H87L pal was therefore included in the study, and was cloned and conjugated into Synechocystis the same way as the other pal CDS.

Cultures of the engineered Synechocystis strains were grown for six days under constant light, and samples for $\mathrm{OD}_{750}$ and LC-MS analysis for $t$ CA and $p$ Cou content in the culture supernatant were taken on days one, three and six (Fig. 3A and B, Table 2). The highest specific production of $t \mathrm{CA}$ was observed by strain AtC, reaching the value of $40.2 \pm 5.6 \mathrm{mg} \mathrm{L}^{-1} \mathrm{OD}^{-1}$ of $t \mathrm{CA}$ at day six (Fig. 3A, Table 2). Western Blot analysis of proteins in the engineered strains at the last day of the experiment (Fig. 3C) showed that expression levels of C-terminally tagged PAL proteins were higher than $\mathrm{N}$-terminally tagged, which correlates with higher titers of the product in most of the cases. The extra bands of smaller molecular size than the PALs may be due to degradation of the detected proteins. The cause of the observed differences in expression levels of the same PAL dependent on the tag position is uncertain. Unpredictability of expression levels is often caused by different 5 UTR $^{\prime}$ sequences, resulting from combination of promoters and RBSs, which together with different coding sequences can create secondary structures restricting efficient ribosome binding [40, 41]. The N-terminal Strep-tag sequence may be expected to even out such context-dependent differences, however, our results showed weaker and more uneven protein expression levels for strains with $\mathrm{N}$-terminally tagged PALs. Another possible explanation is a lower stability of PAL proteins when expressed with $\mathrm{N}$-terminal tag, or that the $\mathrm{N}$-terminal tag sequence affects mRNA stability. The differences in production
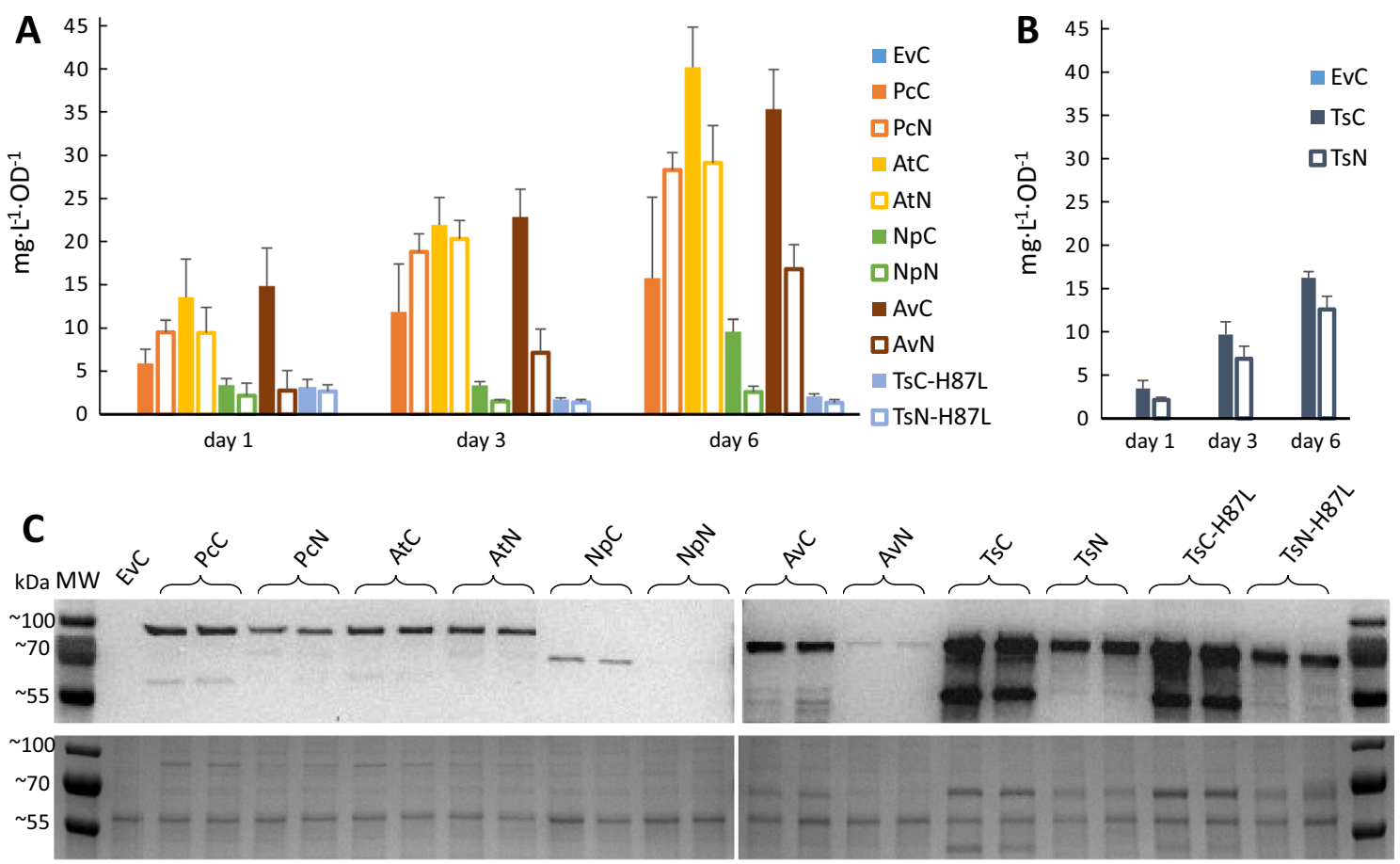

Fig. 3 Productivity and Western Blot of Synechocystis strains overexpressing PAL or TAL from the pEEK vector. A tCA production in strains EvC, PCC, PcN, AtC, AtN, NpC, NpN, AvC, AvN, TsC-H87L and TsN-H87L. B $p$ Cou production in strains TsC and TsN. Samples of growth medium were taken on day one, three and six. The values are the means of three biological replicates and two technical replicates, error bars represent the standard deviation. A and B are plotted using data from Table 2. CWestern Blot and SDS-PAGE of extracts from engineered Synechocystis strains (EvC, PcC, PcN, AtC, AtN, NpC, NpN, AvC, AvN, TsC-H87L, TsN-H87L, TsC and TsN) analyzed for presence of PAL proteins. Upper panel displays the Western Blot using anti-Strep antibody; bottom panel shows the SDS-PAGE loaded with $5 \mu \mathrm{g}$ of soluble fraction from protein crude extract of the different strains 
Table 2 tCA and pCou production by engineered Synechocystis strains after six days of photoautotrophic growth

\begin{tabular}{|c|c|c|c|c|c|}
\hline Strain & $\mathrm{mg} \mathrm{L}^{-1} O D_{750}{ }^{-1}$ & $\mathrm{mg} \mathrm{L}^{-1}$ & Strain & $\mathrm{mg} \mathrm{L}^{-1} O D_{750}{ }^{-1}$ & $\mathrm{mg} \mathrm{L}^{-1}$ \\
\hline \multicolumn{6}{|c|}{$t C A$ production } \\
\hline EvC & N/D & & & & \\
\hline $\mathrm{PCC}$ & $15.8 \pm 9.4$ & $26.3 \pm 13.4$ & Pс3C & $20.7 \pm 3.3$ & $27.5 \pm 4.7$ \\
\hline PCN & $28.3 \pm 2$ & $37.3 \pm 6.1$ & Pc3N & $32.9 \pm 3.2$ & $46.1 \pm 7.6$ \\
\hline AtC & $40.2 \pm 5.6$ & $49.6 \pm 8.7$ & At3C & $32.5 \pm 1.6$ & $41.0 \pm 4.9$ \\
\hline AtN & $29.1 \pm 4.3$ & $35.8 \pm 3$ & At3N & $32.6 \pm 3.6$ & $45.5 \pm 3.2$ \\
\hline $\mathrm{NpC}$ & $9.6 \pm 1.4$ & $14.1 \pm 1.6$ & $\mathrm{~Np} 3 \mathrm{C}$ & $32.7 \pm 5.4$ & $38.0 \pm 7.1$ \\
\hline $\mathrm{NpN}$ & $2.6 \pm 0.7$ & $4.8 \pm 1.4$ & $\mathrm{Np3N}$ & $22.8 \pm 8.5$ & $29.1 \pm 10.6$ \\
\hline $\mathrm{AvC}$ & $35.3 \pm 4.6$ & $46.3 \pm 6.6$ & Av3C & $29.5 \pm 5.1$ & $29.3 \pm 7$ \\
\hline AvN & $16.8 \pm 2.9$ & $26.7 \pm 5.5$ & $A v 3 N$ & $30.7 \pm 9.7$ & $30.2 \pm 13.7$ \\
\hline $\mathrm{TsC}-\mathrm{H} 87 \mathrm{~L}$ & $0.3 \pm 0.3$ & $3.8 \pm 0.7$ & $\mathrm{Ts} 3 \mathrm{C}-\mathrm{H} 87 \mathrm{~L}$ & $4 \pm 0.4$ & $4.7 \pm 0.7$ \\
\hline TsN-H87L & $0.2 \pm 0.3$ & $2.5 \pm 0.7$ & Ts3N-H87L & $2.7 \pm 0.2$ & $3.9 \pm 0.7$ \\
\hline $\mathrm{TsC}$ & Trace amounts & & $\mathrm{Ts} 3 \mathrm{C}$ & Trace amounts & \\
\hline TsN & Trace amounts & & Ts3N & Trace amounts & \\
\hline \multicolumn{6}{|c|}{$p$ Cou production } \\
\hline $\mathrm{TsC}$ & $16.2 \pm 0.7$ & $25.6 \pm 3.9$ & Ts3C & $23.5 \pm 1.2$ & $22.4 \pm 3.2$ \\
\hline $\mathrm{TsN}$ & $12.6 \pm 1.5$ & $19.2 \pm 5.6$ & Ts3N & $22.7 \pm 2.4$ & $28.3 \pm 3.9$ \\
\hline TsC-H87L & N/D & & Ts3C-H87L & N/D & \\
\hline TsN-H87L & N/D & & Ts3N-H87L & N/D & \\
\hline
\end{tabular}

Data corresponds to the panels $A$ and $B$ in Figs. 3 and 5

N/D, none detected

levels of target compounds might also be by virtue of differences in enzyme activity of expressed PALs due to the fused Strep-tag peptide, as the AtN and AtC strains demonstrated similar protein levels but different production of $t$ CA per cell (Fig. 3A and C). The growth of engineered strains which produced more of the molecule of interest per cell over the time of experiment (Fig. 4) was slower compared to the EvC. This result indicates that the expression of PAL protein, which consumes the central metabolite Phe, negatively affects the growth.

The production of $p$ Cou by strains $\mathrm{TsC}$ and TsN showed similar values, although $\mathrm{TsC}$ protein levels were significantly higher than those of the TsN strain (Fig. 3B, Table 2). Substitution of one amino acid residue, H87L, in Ts TAL had successfully switched the enzyme's substrate selectivity from Tyr to Phe. However, the activity of the mutated enzyme variant was decreased compared to a wild type variant, as the productivity per cell decreased nearly eight times, whereas the protein expression levels remained similar (Fig. 3).

\section{Enhancement of $t C A$ production via increase of protein expression level}

Since the productivity in our first experiments seemed to correlate with protein expression levels, to further improve $t$ CA production in Synechocystis we intended to increase protein expression levels of PALs. For this, the pal genes were cloned into two vectors, pEEK3 and pEEK3C, and successfully conjugated into Synechocystis. In pEEK3, the expression is driven by a strong constitutive promotor PtrcCore, followed by a sequence encoding the self-cleaving ribozyme RiboJ [38, 42]. RiboJ causes the transcribed mRNA to undergo cleaving of its own $5^{\prime} \mathrm{UTR}$, which facilitates biding of the ribosome to the RBS of the transcript. Application of RiboJ has been reported to enable a strong, predictable expression in Synechocystis [38, 43].

Comparative growth experiment on these strains demonstrated a similar range of $t$ CA production per cell among all strains, except for the Ts3-H87L strains (Fig. 5A, Table 2). A normalized maximal titer of approx. $32 \mathrm{mg} \mathrm{L}^{-1} \mathrm{OD}^{-1}$ was reached by several strains, namely Pc3N, At3C, At3N, Np3C (Fig. 5A, Table 2). The $p$ Cou specific production titer was increased for Ts3C and Ts $3 \mathrm{~N}$ strains as compared to TsC and TsN strains (Fig. 5B, Table 2). In addition, Western Blot analysis (Fig. 5C) also showed similar expression levels of different PALs with lesser variation dependent on the Strep-tag position. Compared to engineered strains based on overexpression in $\mathrm{pEEK}$, the growth of all engineered strains based on overexpression in pEEK3 showed a larger growth impairment as compared to EvC (Fig. 6). However, the obtained productivity values were lower than the titer achieved for the AtC strain. These findings prompted us to perform a 

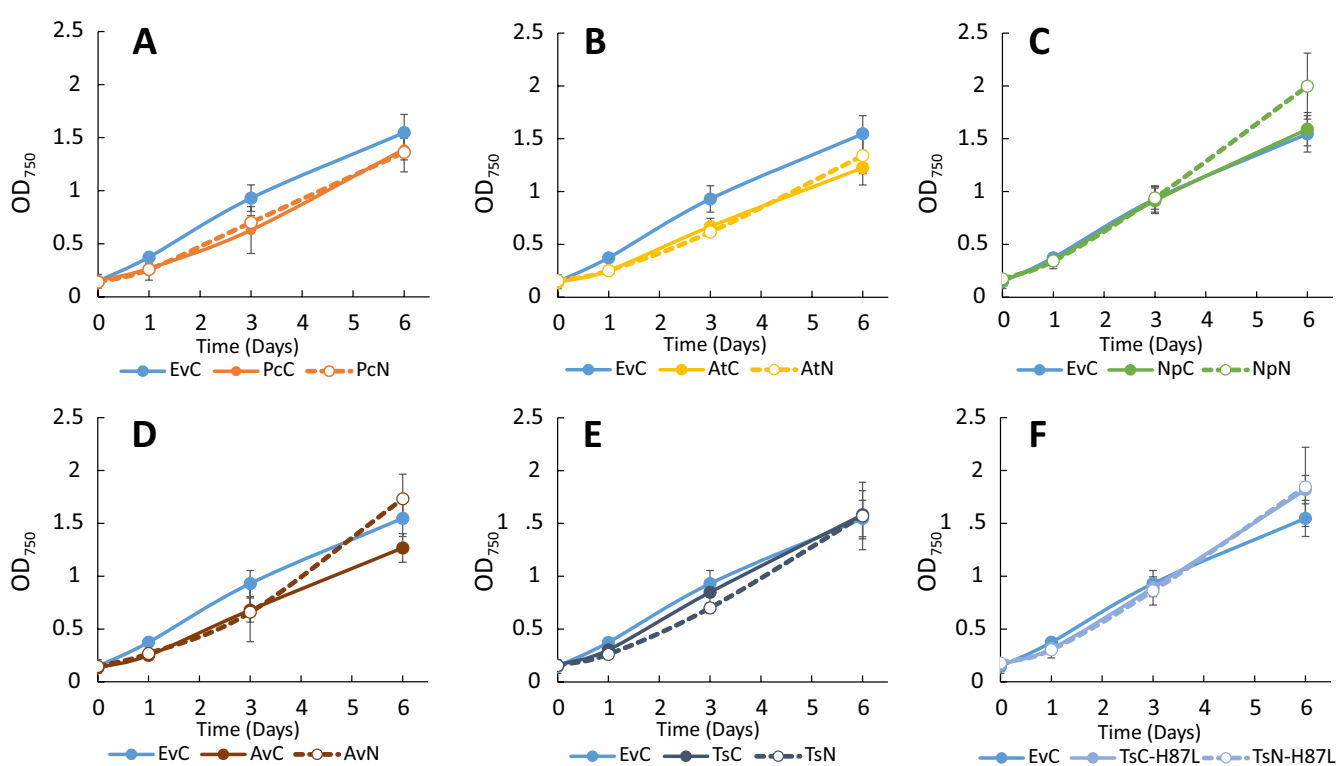

Fig. 4 Growth of Synechocystis strains overexpressing PAL or TAL from the pEEK during 6 days experiment. A Strains EvC, PcC, PcN; B strains EvC AtC, AtN; C strains EvC, NpC, NpN; D strains EvC, AvC, AvN; E strains EvC, TsC TsN; $\mathbf{F}$ strains EvC, Ts3C-H87L and Ts3N-H87L. Results are the mean of three biological replicates, error bars represent standard deviation
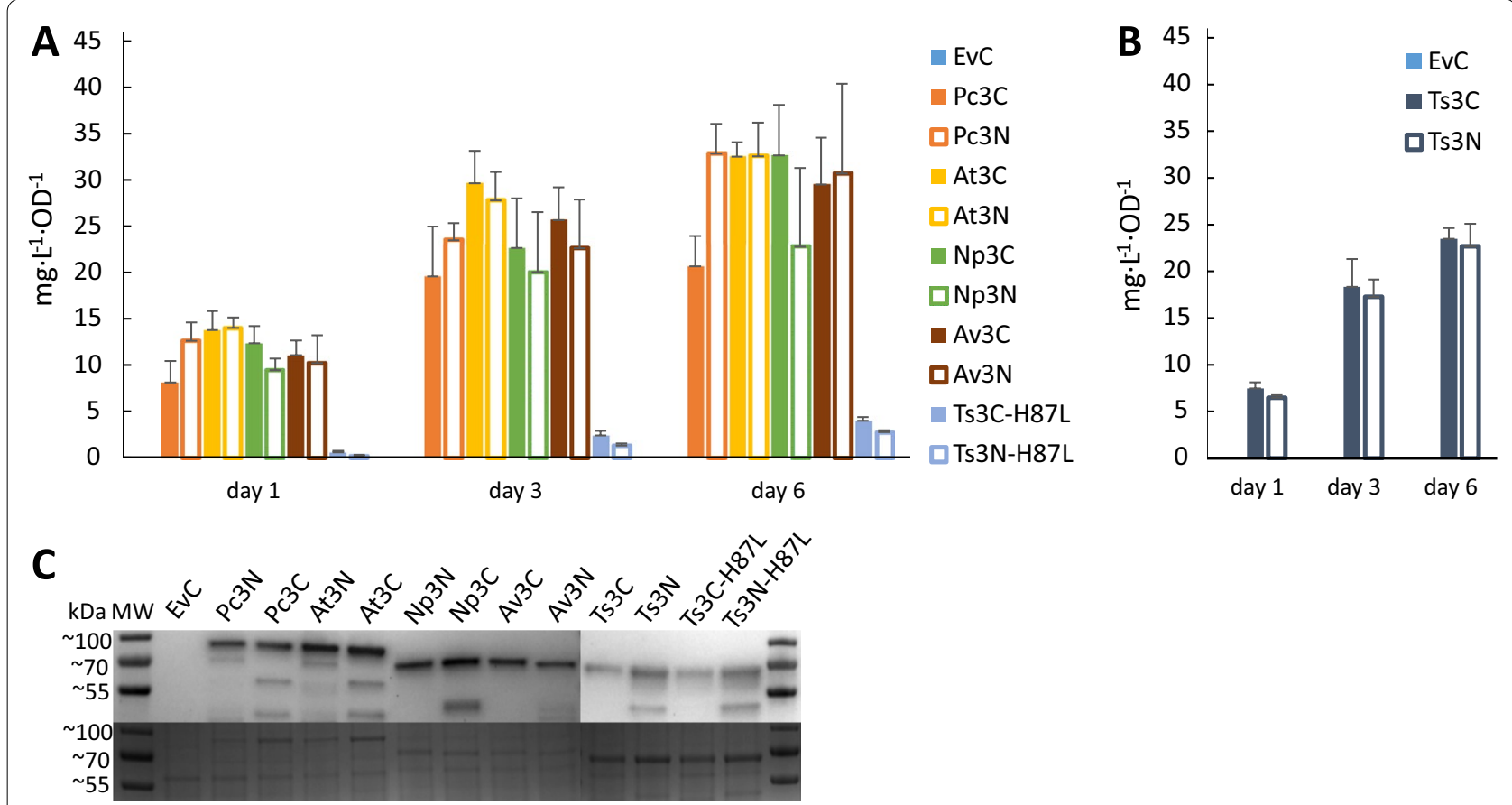

Fig. 5 Productivity and Western Blot of Synechocystis strains overexpressing PAL or TAL from the pEEK3 vector. A Comparison of $t C A$ production in engineered Synechocystis strains EvC, Pc3C, Pc3N, At3C, At3N, Np3C, Np3N, Av3C, Av3N, Ts3C-H87L and Ts3N-H87L. B pCou production in strains $\mathrm{Ts} 3 \mathrm{C}$ and Ts3N. Samples of growth medium were taken on day one, three and six. The values are the means of three biological replicates and two technical replicates, error bars represent the standard deviation. $\mathbf{A}$ and $\mathbf{B}$ are plotted using the data from Table 2. C Western Blot and SDS-PAGE of extracts from engineered Synechocystis strains (EvC, Pc3C, Pc3N, At3C, At3N, Np3C, Np3N, Av3C, Av3N, Ts3C, Ts3N, Ts3C-H87L and Ts3N-H87L) analyzed for presence of PAL proteins. Upper panel displays the Western Blot using anti-Strep antibody; bottom panel shows the SDS-PAGE loaded with $3 \mu \mathrm{g}$ of soluble fraction from protein crude extract of the different strains 

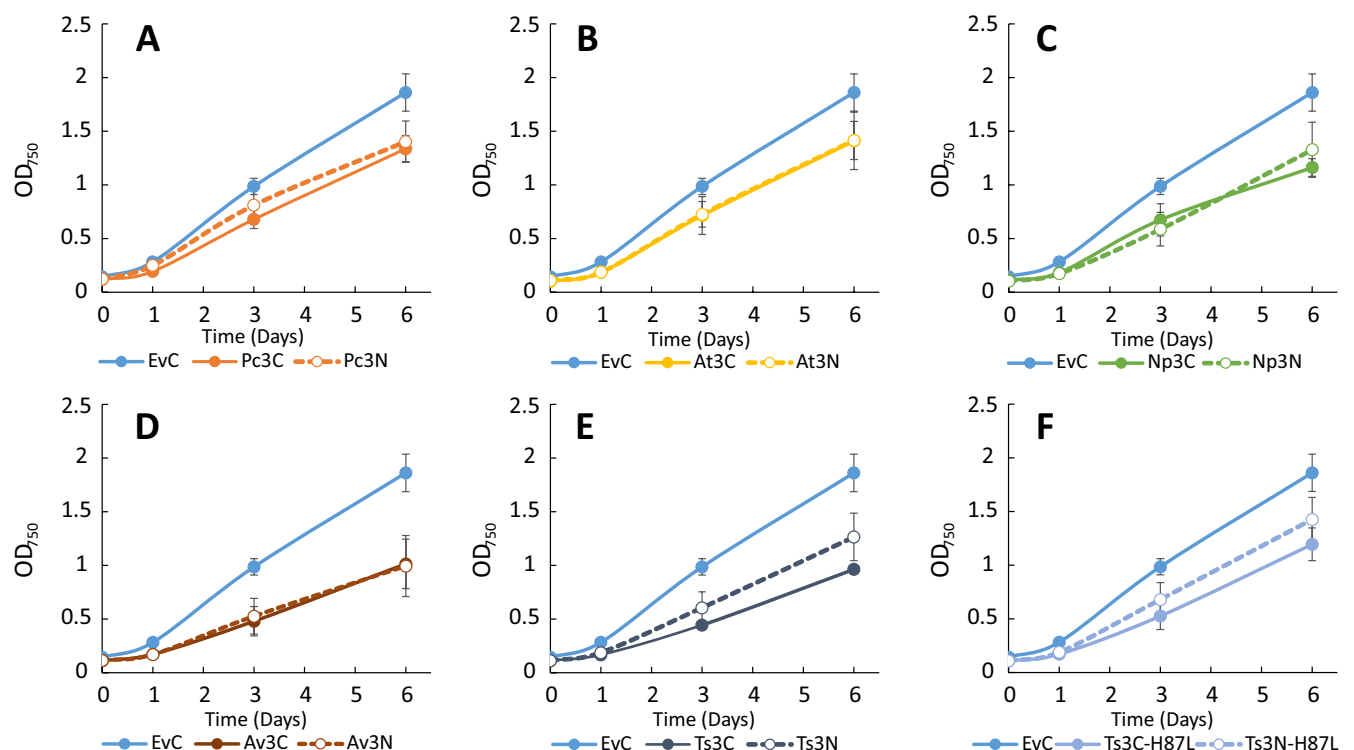

Fig. 6 Growth of Synechocystis strains overexpressing PAL or TAL from the pEEK3 during 6 days experiment. A strains EvC, PC3C, Pc3N; B strains EvC At3C, At3N; C strains EvC, Np3C, Np3N; D strains EvC, Av3C, Av3N; E strains EvC, Ts3C Ts3N; F strains EvC, Ts3C-H87L and Ts3N-H87L. Results are the mean of three biological replicates, error bars represent standard deviation

comparison of the protein expression level for each PAL in all engineered strains. Figure 7 shows the comparative expression of each PAL overexpression variant and we can observe that for all pEEK3 based strains, expression was higher than for corresponding pEEK based strains. The difference in the relative expression levels of the same pEEK3 strains in Figs. 5C, 7 might be due to variation between protein extracts from different biological replicates of same strain. Nonetheless, we can conclude that more PAL protein per cell did not lead to higher $t C A$ productivity, and the usage of RiboJ helped to decrease the differences between $\mathrm{C}$ - and N-terminal Strep-tag position in expression constructs. These results indicate that the PAL expression level does not seem to be the bottleneck of $t$ CA production in Synechocystis. This is further supported by the fact that although all PALs used in this study possess different kinetic parameters as was shown on purified proteins $[18,34,35]$, their overexpression with similar protein levels in Synechocystis resulted in nearly similar production titers of product $t C A$. The apparent limitation once a high enough protein level has been reached might thus be in the intracellular levels of the substrate phenylalanine and the metabolic regulation of its biosynthesis. The obtained production of $40.2 \pm 5.6 \mathrm{mg} \mathrm{L}^{-1} \mathrm{OD}_{750}{ }^{-1}$ of $t \mathrm{CA}$ might represent an experimental maximum under the tested conditions, corresponding to the "limit" of phenylalanine consumption before causing detrimental effect on cell fitness.

\section{Effect of laccase knockout on $t$ CA production}

The discovery by Xue et al. [26] of a laccase enzyme encoded by gene slr1573 in Synechocystis was related to the role of this enzyme in the decomposition of $p$ Cou inside the cell. When the laccase gene was knocked out,

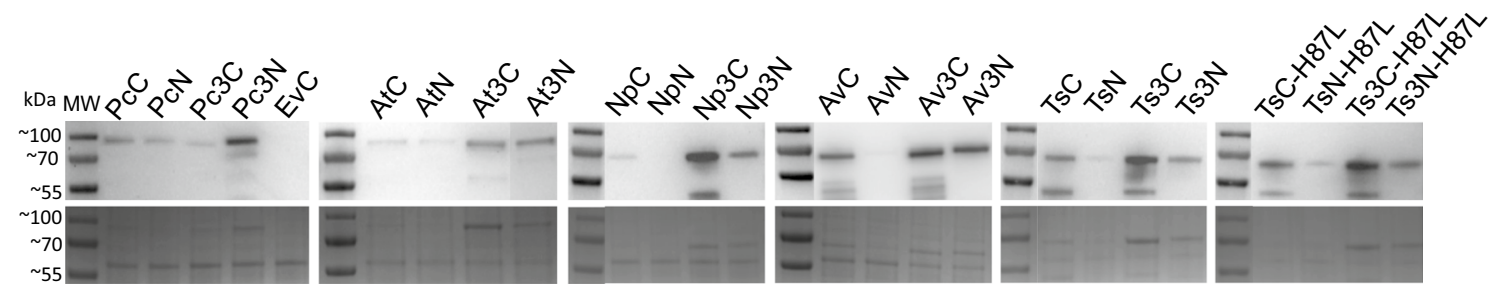

Fig. 7 PAL and TAL relative expression in cell extracts at day six of comparative growth experiments. Upper panel displays the Western Blot using anti-Strep antibody; bottom panel shows the SDS-PAGE loaded with $5 \mu \mathrm{g}$ of soluble fraction from protein crude extract of the different strains, except for strains TsC, TsN, Ts3C, Ts3N, TsC-H87L, TsN-H87L, Ts3C-H87L and Ts3N-H87L where $2 \mu \mathrm{g}$ of protein was loaded 
the authors detected a 25-fold increase in $p$ Cou titer. To assess if the $t$ CA can be decomposed in our engineered strains by the action of the laccase, we constructed an integration plasmid, p1573 (Fig. 2F, Table 1), to knock out this gene in the most prominent producing strains in

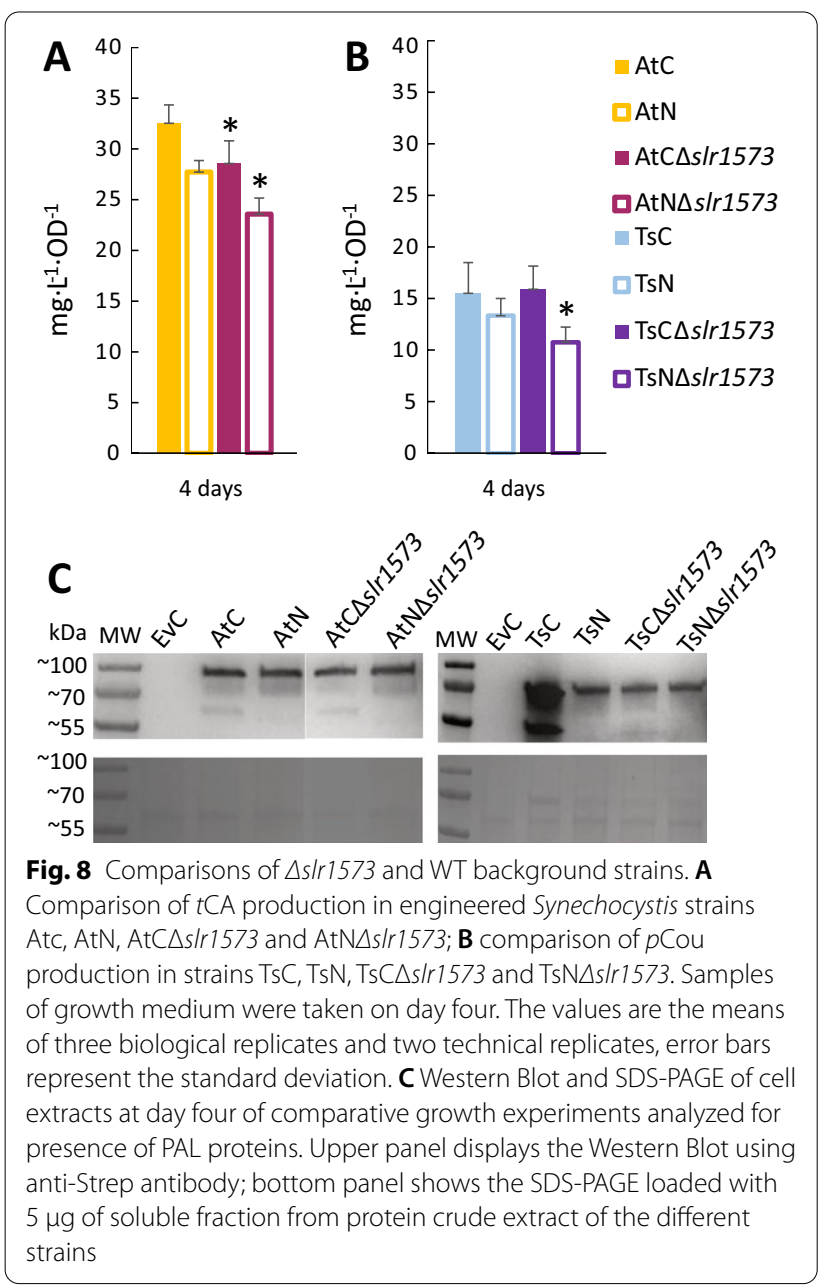

our study-AtC and AtN. TsC and TsN strains were also used as the control strains of $p$ Cou production. The EvC was transformed with the p1573 plasmid to form strain EvC $\Delta$ slr1573, serving as a growth control strain (Table 1).

Comparative growth experiments with the original and laccase knockout strains were performed during four days under constant moderate light intensity of $45 \mu \mathrm{mol}$ photons $\mathrm{m}^{-2} \mathrm{~s}^{-1}$. The productivity on the last days of experiment showed lower $t$ CA and $p$ Cou titers for the $\Delta$ slr1573 strains (Fig. 8). These results are different from what was observed before by Xue et al. [26], where knocking out $\operatorname{slr} 1573$ had a strong positive effect on $p$ Cou titers. Moreover, on the LC-MS profile of $p$ Cou production by $\mathrm{TsC}$ and $\mathrm{TsN}$ strains we did not detect additional peaks that may correspond to the polymerization of 4-vinylphenol as observed by Xue et al. [26]. This difference may however depend on different extraction procedures of $p$ Cou: extraction of media with ethyl acetate $[26,27]$ whereas in our study we subjected the supernatant from the culture directly to LC-MS analysis. With organic solvents extraction in those studies it was possible to extract polymeric compounds with low water solubility. Furthermore, we observed two unidentified peaks of high molecular weight $(\mathrm{m} / \mathrm{z} 323)$ (see Additional file 1: Fig. S2) in the LC-MS profile from all $\Delta$ slr 1573 strains including the control strain EvC $\Delta \operatorname{slr} 1573$ (Fig. 9). These peaks may correspond to the accumulation of phenolic compounds or polymers due to the disruption of their native pathway in the cell.

We also observed a notable difference in phenotype of $\Delta s \sin 1573$ strains compared to the strains with an intact $s l r 1573$. The color of the $\Delta s l r 1573$ strains was comparably more yellowish with less green (Fig. 10A). To address this phenotype difference, we performed a prolonged growth experiment for both control strains as well as pigments quantification. The growth of $\mathrm{EvC} \Delta \operatorname{slr} 1573$ was considerably slower than that of $\mathrm{EvC}$
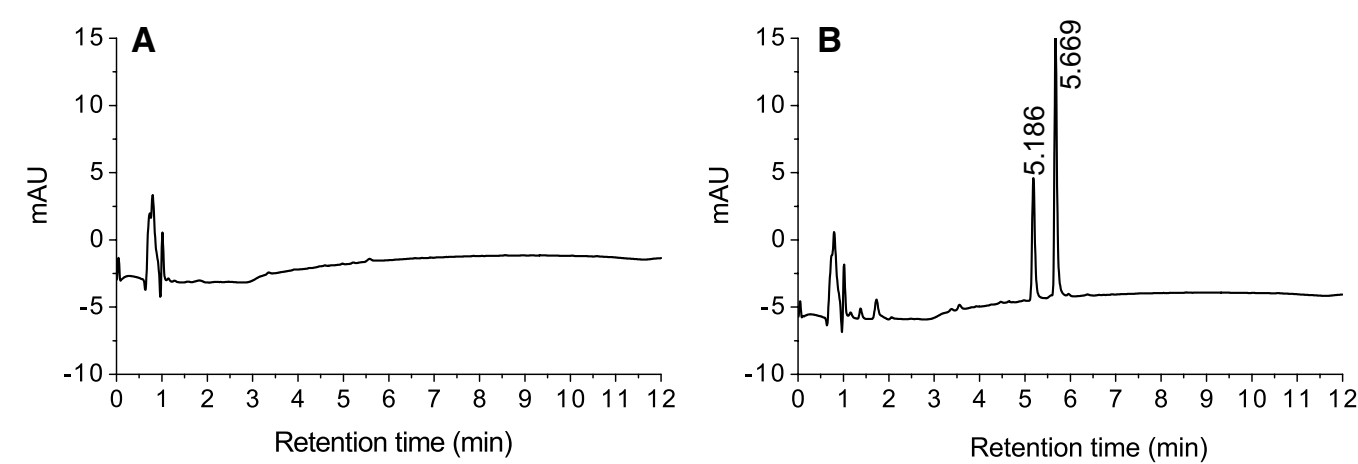

Fig. 9 LC-MS profile of culture medium at $275 \mathrm{~nm}$ wavelength on day four from comparative experiment. A profile from EvC strain; B profile from EvC $\triangle$ sir 1573 strain 

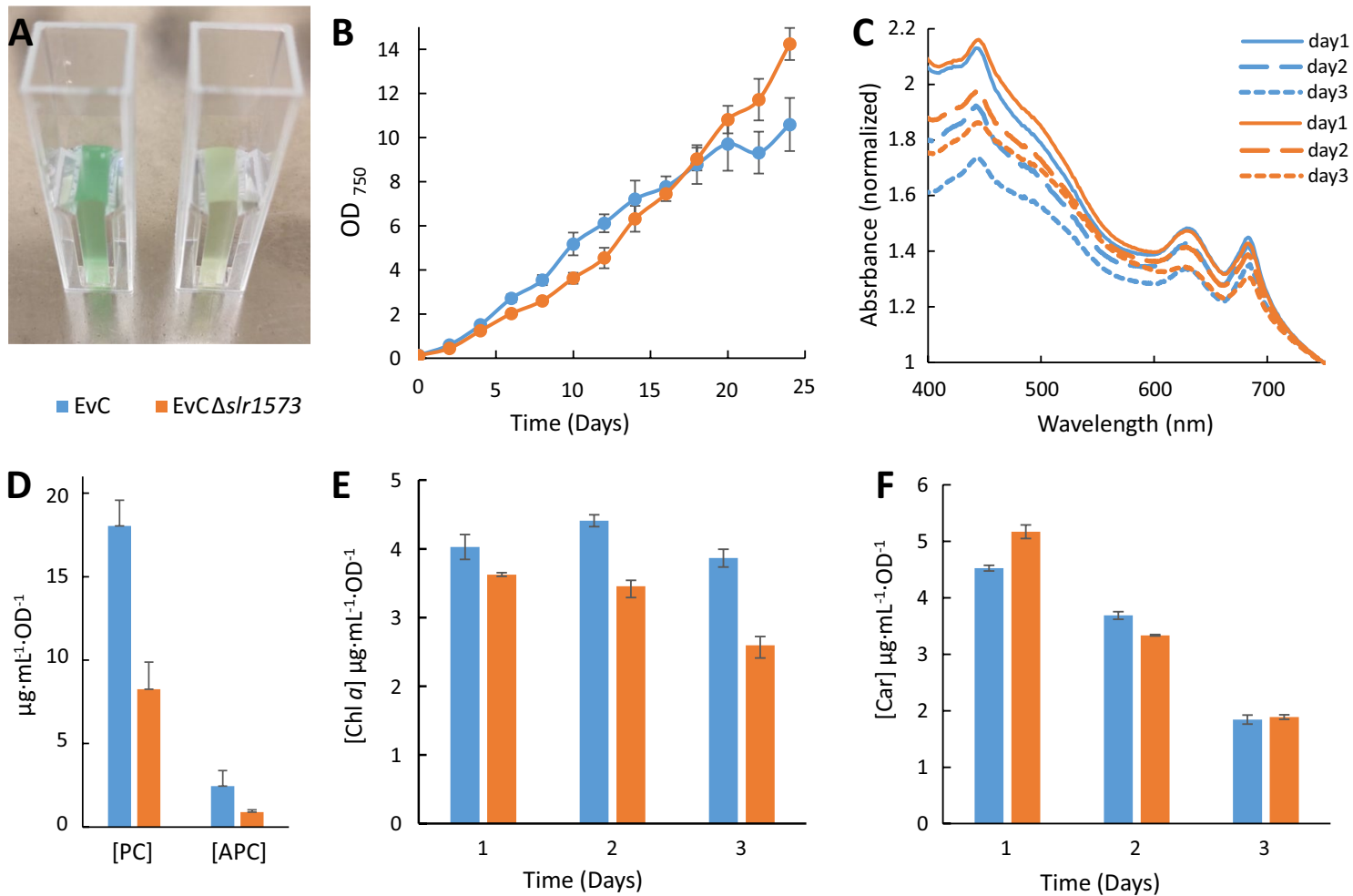

Fig. 10 Comparison of strains EvC to EvC $\triangle$ s/r1573. A Picture of both cultures at $\mathrm{OD}_{750}$ approx. 0.4, left—EvC, right—EvC $\triangle$ s/r1573; B growth curves during 24 days of cultivation; $\mathbf{C}$ whole cell absorbance spectra normalized at $750 \mathrm{~nm}$; $\mathbf{D}$ phycobiliprotein concentration normalized per $\mathrm{OD}_{750}$ taken at day 3; $\mathbf{E}$ Chlorophyll a content normalized per $\mathrm{OD}_{750} ; \mathbf{F}$ total carotenoid content normalized per $\mathrm{OD}_{750}$

in the first half of the linear phase (Fig. 10B).Whole cell absorbance spectra was measured in the beginning of the growth experiment, before both cultures reached an $\mathrm{OD}_{750}$ of 1 , as for older cultures a shading effect may contribute to the difference in pigment content. The recorded spectra showed distinct absorbance patterns for the two strains (Fig. 10C). Pigment content quantification was also carried out at the same time points as the whole spectra. The results (Fig. 10D-F) showed that $\mathrm{EvC} \Delta$ slr 1573 strain has markedly less phycobiliproteins as well as less chlorophyll $a$ per cell, while carotenoid content was higher, although only in the beginning of the experiment. It is not clear what mechanisms cause these effects, whether it is a direct effect on the pigment synthesis or regulation in the cell, or a secondary effect due to stress conditions caused by the deletion of slr1573.

All together, the abovementioned data indicate that deletion of the slr1573 laccase in Synechocystis has a clear impact on the cells, which has not been previously reported. Although laccases and laccases-like enzymes are very abundant in nature and have many diverse functions, their role in bacteria, and especially in cyanobacteria has not been investigated extensively [44].

\section{Production of $t C A$ under small-scale high density cultivation (HDC) conditions}

The specific production titers of $t \mathrm{CA}$ and $p$ Cou obtained in the above described experiments are lower compared to those that were reported previously, although we find it difficult to compare them due to different normalization and growth conditions used. The levels of $t \mathrm{CA}$ and $p$ Cou produced in cyanobacteria reported to date are: $114 \mathrm{mg} \mathrm{L}^{-1}\left(267 \pm 31 \mathrm{mg} \mathrm{gDW}^{-1}\right)$ of $t \mathrm{CA}$ and $207 \mathrm{mg} \mathrm{L}^{-1}$ $\left(470 \pm 70 \mathrm{mg} \mathrm{gDW}^{-1}\right)$ of $p$ Cou obtained after growth in Multi-cultivator MC 1000OD, under $100 \mu \mathrm{mol}$ photons $\mathrm{m}^{-2} \mathrm{~s}^{-1}$ and with air enriched with $3 \%(\mathrm{v} / \mathrm{v}) \mathrm{CO}_{2}$ [25]; $197 \mathrm{mg} \mathrm{L}^{-1}$ of $p$ Cou after 7 days of cultivation under $50 \mu \mathrm{mol}$ photons $\mathrm{m}^{-2} \mathrm{~s}^{-1}$ [27]; $82.6 \mathrm{mg} \mathrm{L}^{-1}$ of $p$ Cou after 7 day cultivation under $50 \mu \mathrm{mol}$ photons $\mathrm{m}^{-2} \mathrm{~s}^{-1}$ with $5 \mathrm{mM}$ glucose supplementation in the media [26].

Therefore, we intended to test whether we can reach high volumetric titer of molecules of interest using improved growth conditions, such as small-scale highdensity cultivation. We used a cultivation system from CellDEG (www.celldeg.com) (Fig. 11A), which has been used to overcome crucial high-density cultivation limitations such as $\mathrm{CO}_{2}$ supply and uneven light distribution in dense cultures for successful production of cyanophycin 

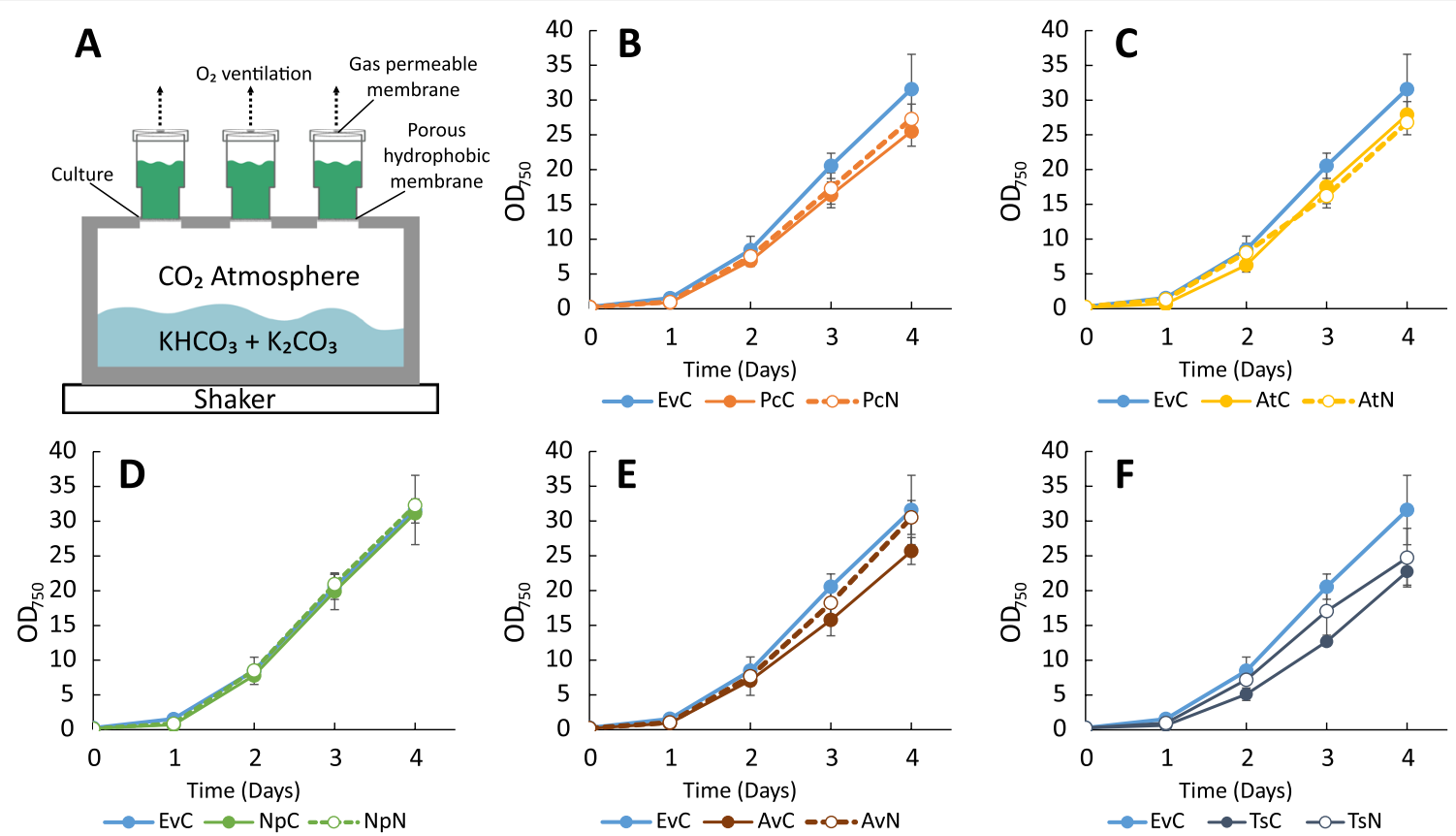

Fig. 11 Growth of Synechocystis engineered strains during high-density cultivation for 4 days. A schematic representation of the CellDeg HDC $6.10 \mathrm{~B}$ system. The cultivation bath is filled with $3 \mathrm{M}$ carbonate buffer and constantly creates a $\mathrm{CO}_{2}$ rich atmosphere with diffuses through a porous hydrophobic membrane to the culture medium. Oxygen ventilation of growing cultures is provided by gas permeable membrane outlet on the lid of cultivation vessel. B growth of strains EvC, PcC, PcN; C strains EvC AtC, AtN; $\mathbf{D}$ strains EvC, NpC, NpN; E strains EvC, AvC, AvN; $\mathbf{F}$ strains EvC, TsC TsN. For each strain at least two independent cultivations experiments with biological triplicates was carried out. Error bars represent standard deviation

and terpenoids reaching ultra-high cell densities in a short period of time [31-33].

For HDC experiments, we used the production strains based on the pEEK expression vectors. The Ts-H87L strains were not included since the productivity of $t \mathrm{CA}$ was the lowest for those. The cultures of engineered Synechocystis were grown for four days, and samples for LC-MS were taken on days two and four. Figure 11B-F displays the growth curves, where the culture density after four days of cultivation reached values in the range of $\mathrm{OD}_{750} 25-32$. Similarly to what was observed before (Fig. 4), the growth pattern of engineered strains that had the least productivity showed similar growth to the $\mathrm{EvC}(\mathrm{NpC}$ and $\mathrm{NpN})$ whereas the other reached lower OD compared to EvC. The productivity results (Fig. 12, Table 3) showed that the specific $t \mathrm{CA}$ and $p$ Cou titers at the end of experiment are lower than during the Erlenmeyer-flask cultivation for each corresponding strain. The relative expression of PALs (Fig. 12C) showed considerably higher protein levels in strains $\mathrm{AvC}$ and $\mathrm{PcC}$ than $A t C$, which presumably led to higher $t C A$ titer per cell than in the AtC strain, unlike the results from standard growth conditions where strain AtC had the highest production.

Although the specific production titer was compromised for HDC, as it was observed previously
[32], the high biomass accumulation rate resulted in high total product yield of $797.8 \pm 153.3 \mathrm{mg} \mathrm{L}^{-1}$ and $411.6 \pm 94.9 \mathrm{mg} \mathrm{L}^{-1}$ of $t \mathrm{CA}$ and $p$ Cou respectively (Table 3), which is the highest reported in cyanobacteria so far. In summary, this experiment shows a great potential for obtaining high volumetric concentrations of a product of interest via optimized growth conditions, allowing the cultures to reach very high biomass concentration within a short time period.

\section{Conclusions}

In this study we aimed to express several pal genes in Synechocystis and subsequently evaluate the production of $t \mathrm{CA}$ by engineered strains in order to select the best performing candidate. Out of five selected pal genes from different organisms, PAL from Treponema socranskii turned out to be a TAL, but a single amino acid substitution in substrate selectivity switch position was sufficient to change the substrate preference to Phe. Comparative growth and production experiments showed that the best performing stain was AtC with the specific production of $40.2 \pm 5.6 \mathrm{mg} \mathrm{L}^{-1} \mathrm{OD}_{750}^{-1}$ in six days. Further improvement of productivity by the increase of expression levels of PAL proteins did not result in higher specific production titers, although several strains showed nearly similar productivity due to similar relative PALs 

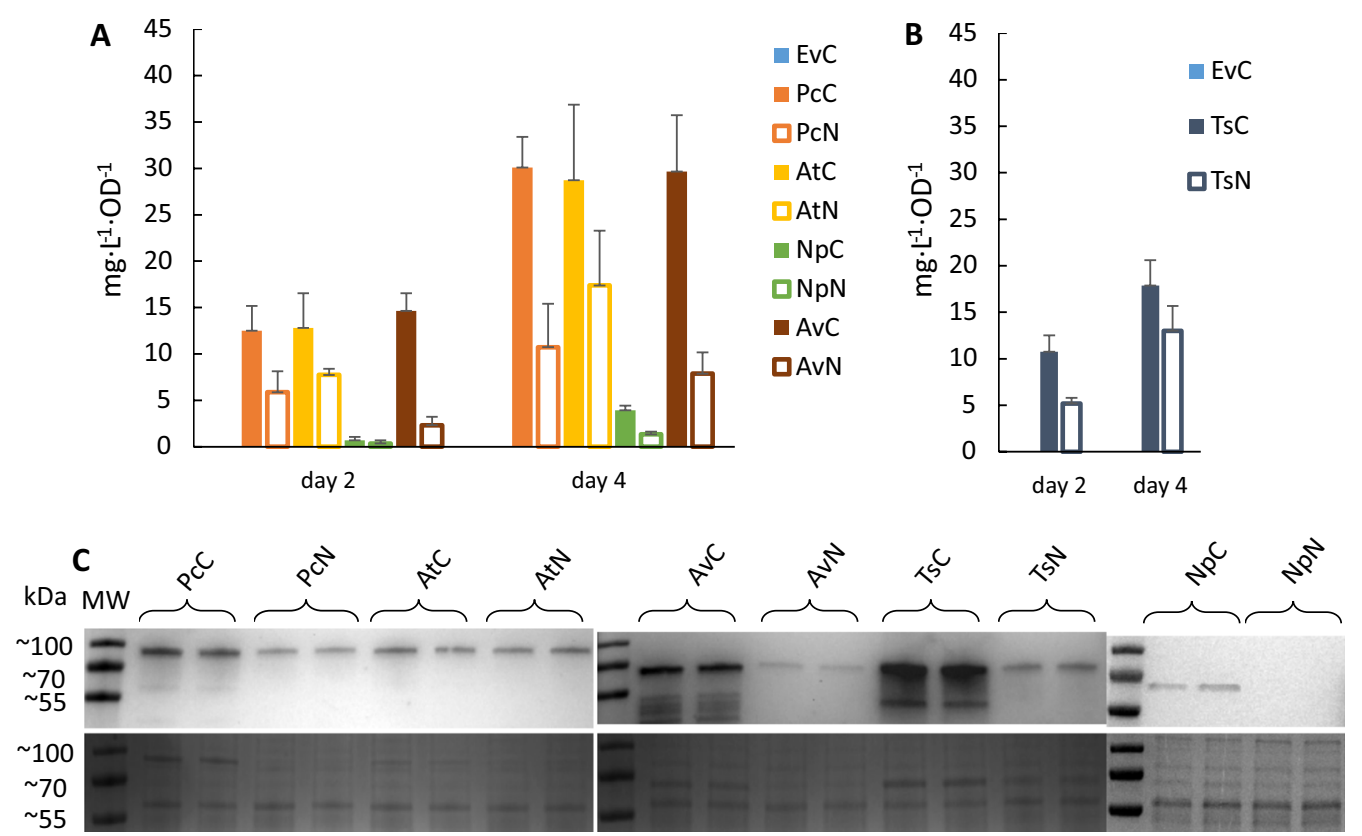

Fig. $12 t C A$ and $p$ Cou production and Western Blot of engineered Synechocystis strains during high-density cultivation experiments. A tCA production in engineered Synechocystis strains EvC, PcC, PcN, AtC, AtN, NpC, NpN, AvC, AvN. B pCou production in strains TsC and TsN. Samples of growth medium were taken on day two and four. The values are the means of three biological replicates and two technical replicates, error bars represent the standard deviation. CWesternBlot and SDS-PAGE of extracts from engineered Synechocystis strains (EvC, PcC, PcN, AtC, AtN, NpC, $\mathrm{NpN}, \mathrm{AvC}, \mathrm{AvN}, \mathrm{Ts} \mathrm{C}$ and $\mathrm{Ts} \mathrm{N}$ ) analyzed for presence of PAL proteins taken on day 4 of HDC experiment. Upper panel displays the Western Blot using anti-Strep antibody; bottom panel shows the SDS-PAGE loaded with $3 \mu \mathrm{g}$ of soluble fraction from protein crude extract of the different strains

Table 3 tCA and $p$ Cou production by engineered Synechocystis strains after four days of high-density cultivation

\begin{tabular}{|c|c|c|}
\hline Strain & $\mathrm{mg} \mathrm{L}^{-1} \mathrm{OD}_{750}{ }^{-1}$ & $\mathrm{mg} \mathrm{L}^{-1}$ \\
\hline \multicolumn{3}{|c|}{ tCA production } \\
\hline EvC & N/D & \\
\hline PCC & $30.1 \pm 3.3$ & $746.6 \pm 51.2$ \\
\hline $\mathrm{PCN}$ & $13.1 \pm 2.4$ & $369.9 \pm 83.8$ \\
\hline AtC & $28.7 \pm 8.2$ & $771.3 \pm 233.9$ \\
\hline AtN & $17.4 \pm 5.9$ & $539.3 \pm 134.1$ \\
\hline $\mathrm{NpC}$ & $3.9 \pm 0.5$ & $123.4 \pm 19.8$ \\
\hline NpN & $1.3 \pm 0.3$ & $43 \pm 9$ \\
\hline$A v C$ & $29.7 \pm 6.1$ & $797.8 \pm 153.3$ \\
\hline AvN & $7.9 \pm 2.3$ & $238.0 \pm 62.5$ \\
\hline \multicolumn{3}{|c|}{$p$ Cou production } \\
\hline $\mathrm{TsC}$ & $17.9 \pm 2.7$ & $411.6 \pm 94.9$ \\
\hline TsN & $13 \pm 2.7$ & $313 \pm 35.3$ \\
\hline
\end{tabular}

Data correspond to the panels A and B in Fig. 12

$\mathrm{N} / \mathrm{D}$, none detected

expression. Knock-out of the slr1573 laccase gene, which has been suggested to be active in the degradation of synthetized $t \mathrm{CA}$ and $p$ Cou, did not result in any improvement of productivity. However, we could observe strong phenotype of slower growth and lower pigments content for the strains lacking the $\operatorname{slr} 1573$ laccase. The application of a high-density cultivation platform for growth of the engineered strains resulted in a remarkably high $t \mathrm{CA}$ volumetric titers of $797.8 \pm 153.3 \mathrm{mg} \mathrm{L}^{-1}$ by strain $\mathrm{AvC}$, consistent with the central role of Phe in the cell metabolism which ensures a high flux of precursors for its synthesis, and subsequently for the production of $t \mathrm{CA}$. In summary, this work contributes to the development of cyanobacteria as cell factories for sustainable conversion of $\mathrm{CO}_{2}$ into phenylpropanoids.

\section{Methods}

\section{Bacterial strains and growth conditions}

Escherichia coli DH5 $\alpha \mathrm{Z1}$ (Invitrogen) was used for subcloning and conjugation. Escherichia coli cells were grown in LB medium at $37{ }^{\circ} \mathrm{C}$ and supplemented with appropriate antibiotics to the final concentrations in the medium: $50 \mu \mathrm{g} \mathrm{ml}^{-1}$ kanamycin $(\mathrm{Km})$ or/and $20 \mu \mathrm{g} \mathrm{ml}^{-1}$ chloramphenicol (Cm) (Sigma, Merk).

Synechocystis sp. PCC 6803, a unicellular glucose-tolerant strain was used in this study. Cultures were grown in BG11 medium [45] with respective antibiotics $\mathrm{Km}$ $25 \mu \mathrm{g} \mathrm{ml}^{-1}$ and/or $\mathrm{Cm} 20 \mu \mathrm{g} \mathrm{ml}^{-1}$ at $30^{\circ} \mathrm{C}$ under constant light. The optical density of Synechocystis cultures 
at $750 \mathrm{~nm}$ was measured using a Varian Cary $50 \mathrm{BIO}$ spectrophotometer, and an $\mathrm{OD}_{750}$ value of 1 corresponds to approximately $10^{8}$ cells.

\section{Construction of plasmids for gene expression}

The broad host range self-replicative vectors $\mathrm{pEEK}$ and pEEK3 [37] (also Englund E., not published) which are based on the vector PPMQAK1 [46] were used in this study as shuttle vectors (Fig. 2). The pEEK vector carries a Strep-tag with glycine-serine linker at the C-terminus position and the counter-selection marker $c c d B$ between $\mathrm{XbaI}$ and BglII site. The expression is driven by a strong constitutive promotor $\mathrm{Ptrc} 2 \mathrm{O}$ and the translation is initiated from the synthetic ribosomal binding site RBS* [47]. In order to evaluate an optimal condition of PAL proteins activity, another vector pEEKN was constructed, which in contrast to pEEK, can be used to place a Strep-tag at the $\mathrm{N}$-terminus, and the $c c d B$ sequence is flanked by BamHI and SpeI. Vector pEEK3 is different from pEEK and $\mathrm{pEEKN}$ by containing the strong constitutive promotor PtrcCore and a RiboJ element to give strong reliable expression [42]. Based on pEEK3 another vector pEEK3C was constructed, where downstream of RiboJ sequence strong bacterial RBS [48] is placed, followed by XbaI and BglII restriction sites flanking $c c d B$ sequence and a glycine-serine linker with Strep-tag placed at the C-terminus of the expressed protein.

pal from Nostoc punctiforme ATCC 29133/PCC 73102 (UniProtKB-B2J528) was amplified using genomic DNA as a template. The rest of the pal genes used in this study, from Arabidopsis thaliana (UniProtKB-P45724), Petroselinum crispum (UniProtKB-P24481), Anabaena variabilis ATCC 29413/PCC 7937 (Trichormus variabilis) (UniProtKB-Q3M5Z3) and Treponema socranskii subsp. paredis ATCC 35535 (UniProtKB-S3JNX8), were codon optimized using Gene Designer (DNA2.0) software for heterologous expression in Synechocystis and synthesized by GenScript.

Genes were inserted into plasmids using SpeI and BamHI (pEEK), BamHI, and SpeI (pEEK3) restriction sites. For insertion into pEEK3C vector, genes were likewise digested with SpeI and BamHI, but ligated into XbaI and BglII sites on the plasmid backbone, resulting in creation of the TCTAGT and GGATCT scars, respectively. For insertion into pEEKN, BglII and SpeI restriction sites were used for Pc, At and Av pals, BamHI and SpeI for $N p$ pal, BglII and PstI for Ts tal.

Site directed mutagenesis of Ts tal sequence was performed with Ts tal cloned into pEEK and pEEKN as template using $5^{\prime}$ 'phosphorelated primers carrying overhang for substitution of two nucleotides at position Histidine 87 to create Leucine 87. The linear DNA fragment was then ligated and transformed in E. coli.
The laccase oxidase encoded by open reading frame slr1573 in Synechocystis [26] was knocked out by replacing the gene with a $\mathrm{Cm}$ resistance cassette. For this, $1 \mathrm{~kb}$ flanking regions upstream and downstream of $\operatorname{sir} 1573$ gene were amplified from Synechocystis genomic DNA and cloned into integrative vector pEERM3 [39] creating the plasmid p1573 (Fig. 2F).

\section{Conjugation and transformation of Synechocystis}

For conjugation, overnight cultures of $E$. coli cargo cells and E. coli HB101 helper cells with pRL443-Amp ${ }^{\mathrm{R}}$ plasmid were centrifuged at $5000 \mathrm{rpm}$ for $5 \mathrm{~min}$ and resuspended in fresh LB medium without antibiotics. A mixture of cargo cells $(1 \mathrm{ml})$, helper cells $(1 \mathrm{ml})$ and wild-type Synechocystis PCC $6803(200 \mu \mathrm{l})$ was incubated under $100 \mu \mathrm{mol}$ photons $\mathrm{m}^{-2} \mathrm{~s}^{-1}$ at $30{ }^{\circ} \mathrm{C}$ for $2 \mathrm{~h}$. The mixture was then spread on a filter on a BG11 agar plate without antibiotics for another $24 \mathrm{~h}$ of incubation. For colony selection, the filters were changed onto new BG11 agar plates with $50 \mu \mathrm{g} \mathrm{ml}^{-1} \mathrm{Km}$. Colonies appeared after 1-2 weeks and were screened by PCR using gene specific primers and DreamTaq DNA polymerase (Thermo Fisher Scientific). Positive colonies were inoculated in fresh liquid BG11 medium with $25 \mu \mathrm{g} \mathrm{ml}^{-1} \mathrm{Km}$.

For transformation, Synechocystis engineered strains possessing already the $\mathrm{Km}$ resistance, were transformed with p1573 as described previously [46]. Colonies that appeared after 10-14 days were analyzed using PCR and restreaked on plates repeatedly until full segregation was reached.

\section{Determination of $t C A$ and $p$ Cou by LC-MS}

Determination of $t \mathrm{CA}$ and $p \mathrm{Cou}$ in the growth media was performed by LC-MS. For this $1 \mathrm{ml}$ of supernatant was taken from Synechocystis cultures at certain days of experiment, samples were filtered through $0.2 \mu \mathrm{m}$ pore PTFE filters (Fisherbrand) and subjected to HPLC analysis. Samples were stored at $-20{ }^{\circ} \mathrm{C}$ if not analyzed the same day.

For qualitative analysis of $E$. coli strains for the presence of corresponding compounds, $3 \mathrm{ml}$ of liquid cultures were inoculated from overnight seed cultures, grown until $\mathrm{OD}_{600} \sim 1$ and induced with $1 \mathrm{mM}$ of IPTG (Sigma, Merk). After induction, cells were grown for another $3 \mathrm{~h}$ and $1 \mathrm{ml}$ of supernatant was collected. The samples were treated analogously as of Synechocystis cultures.

HPLC-MS analysis was performed using an Agilent 1290 Infinity II HPLC system equipped with a 1290 Infinity II High Speed pump and a 1260 II Infinity DAD HS UV-vis detector, using an InfinityLab POROSHELL SB-120 C18 column with dimensions of $50 \mathrm{~mm} \times 2.1 \mathrm{~mm}$ and $2.7 \mu \mathrm{m}$ particle size. The HPLC was coupled to an InfinityLab LC/MSD equipped with an ESI ionization 
source. LC separation was performed using a water (A, $0.1 \%$ formic acid) and acetonitrile (B) eluent system using the method: $0-1 \mathrm{~min} 10 \% \mathrm{~B} ; 1-10 \mathrm{~min} 10 \rightarrow 90 \% \mathrm{~B}$; $10-11$ min $90 \%$ B; $11-11.1 \mathrm{~min} 90-10 \%$ B, $11.1-12$ min $10 \% \mathrm{~B}$; at the flow rate of $0.3 \mathrm{ml} / \mathrm{min}$. The quantification of $t \mathrm{CA}$ and $p \mathrm{Cou}$ in Synechocystis cultures was based on a linear calibration curve from standards measured in technical triplicates. Standards for $t \mathrm{CA}$ and $p \mathrm{Cou}$ (Sigma, Merk) were prepared in BG11 medium in the range $1-100 \mu \mathrm{g} \cdot \mathrm{ml}^{-1}$ and filtered before analysis.

\section{Western blot (WB) analysis}

Proteins from Synechocystis cells were extracted on the last day of the experiment as described by Ivleva and Golden 2007 [49], and the soluble fraction from the crude cell extracts was used further for the analysis. Protein quantification was performed with DC protein assay (Bio-Rad), using albumin from bovine serum (Sigma) as a standard. Soluble proteins were separated by SDS-PAGE, using Mini-PROTEAN TGX ${ }^{\mathrm{TM}}$ gels (Bio-Rad), and transferred to PVDF membrane (Bio-Rad.) Immunoblot was performed according to standard techniques using AntiStrep-tag II (Abcam) for the detection of Strep-tagged proteins.

\section{Pigments quantification}

To determine pigment content in strains $\mathrm{EvC}$ and EvC $\Delta$ slr1573, the pre-cultures inoculated from cryostocks were grown in triplicates under $45 \mu \mathrm{mol}$ photons $\mathrm{m}^{-2} \mathrm{~s}^{-1}$ for several days. Then, cultures were re-inoculated with fresh media to the starting $\mathrm{OD}_{750} \sim 0.1$. Samples for chlorophyll $a$ and carotenoid quantification $(1 \mathrm{ml})$ were collected in triplicates on the day after starting the experiment (day 1) and the following two days (day 2 and day 3), until the cultures reached $\mathrm{OD}_{750} \sim 1$. The cells were then centrifuged for $2 \mathrm{~min}$ at $15,000 \times g$, the supernatant was removed and $1 \mathrm{ml}$ of methanol $100 \%$ (Alpha Aesar) was added. Samples were homogenized and incubated in dark at $4{ }^{\circ} \mathrm{C}$ for at least $30 \mathrm{~min}$. After incubation, the samples were centrifuged for $10 \mathrm{~min}$ at $15,000 \times g$ at $4{ }^{\circ} \mathrm{C}$, and the supernatant was then used to measure absorbance at $470 \mathrm{~nm}, 665 \mathrm{~nm}$ and $720 \mathrm{~nm}$ in a Varian Cary 50 BIO spectrophotometer, using methanol as blank. Concentration of chlorophyll $a$ and carotenoids were calculated according to Ritchie et al. [50] and Wellburn et al. [51] respectively.

For phycobiliproteins determination, culture samples $(2 \mathrm{ml})$ were collected at day 3 in triplicates and centrifuged at $15,000 \times g$ for $2 \mathrm{~min}$. The supernatant was discarded and acid-washed glass beads (425-600 $\mu \mathrm{m}$ diameter, Sigma-Aldrich) were added to the sample together with $200 \mu \mathrm{l}$ of PBS solution. The cells were disrupted using the Precellys-24 Beadbeater (Bertin
Instruments) using program $3 \times 30 \mathrm{~s}$. Then $800 \mu \mathrm{l}$ of PBS was added to the sample, the mixture was mixed vigorously and incubated for at least $1 \mathrm{~h}$. After, the samples were centrifuged for $5 \mathrm{~min}$, the supernatant transferred to a new tube and centrifuged at maximum speed for $30 \mathrm{~min}$ at $4{ }^{\circ} \mathrm{C}$. The absorbance values at $652 \mathrm{~nm}$ and $615 \mathrm{~nm}$ were measured and concentration of allophycocyanin (APC) and phycocyanin (PC) was determined according to Bennet and Bogorad [52].

\section{High-density cultivation}

For the small-scale high-density cultivation an HDC 6.10 starter kit (CellDEG, Germany) was used. The kit consist of $10 \mathrm{ml}$ cultivation vessels with porous hydrophobic membrane at the bottom and a buffer reservoir which was filled with $200 \mathrm{ml}$ of a $3 \mathrm{M} \mathrm{KHCO}_{3} / 3 \mathrm{M} \mathrm{K}_{2} \mathrm{CO}_{3}$ (9:1 ratio) solution to provide 90 mbar partial pressure of $\mathrm{CO}_{2}$ (reference $\mathrm{T}=20{ }^{\circ} \mathrm{C}$, according to the manufacturer's recommendation). The nutrient-enriched media was prepared as described in Lippi et al. [33] with slight modifications: as an iron source ammonium iron (III) citrate was used and sodium nitrate as a sole nitrate source.

The cultivation was carried out in a "Versatile Environmental Test Chamber" (Sanyo) w/o humidifier at $30{ }^{\circ} \mathrm{C}$ under multidirectional illumination with fluorescent white light with increasing light intensities: $250 \mu \mathrm{E} \mathrm{m}^{-2} \mathrm{~s}^{-1}(0-24 \mathrm{~h}), 490 \mu \mathrm{E} \mathrm{m} \mathrm{m}^{-2} \mathrm{~s}^{-1}(24-48 \mathrm{~h})$, $750 \mu \mathrm{E} \mathrm{m}^{-2} \mathrm{~s}^{-1}(48-96 \mathrm{~h})$. The CellDEG system was shaking constantly at $320 \mathrm{rpm}$ (IKA KS 130 basic orbital shaker $\varnothing=4 \mathrm{~mm}$ ).

\section{Abbreviations}

AAA: Aromatic amino acids; APC: Allophycocyanin; At: Arabidopsis thaliana; Av: Anabaena variabilis; C4H: Cinnamate-4-hydroxylase; CBB cycle: Calvin-Benson-Bassham cycle; Cm: Chloramphenicol; DAHP: 3-DeoxyD-arabinoheptulosonate 7-phosphate synthase; E. coli: Escherichia coli; E4P: Erythrose-4-phosphate; EPSP: 5-Enolpyruvylshikimate-3-phosphate synthase; HAL: Histidine ammonia lyase; HDC: High-density cultivation; Km: Kanamycin; MIO: 3,5-Dihydro-5-methylidine-4H-imidazol-4-one; Np: Nostoc punctiforme; PAL: Phenylalanine ammonia lyase; PC: Petroselinum crispum; PC: Phycocyanin; pCou: $p$-Coumaric acid; PEP: Phosphoenolpyruvate; Phe: Phenylalanine; PQ: Plastoquinone; Synechocystis: Synechocystis sp. PCC 6803; TAL: Tyrosine ammonia lyase; tCA: trans-Cinnamic acid; Trp: Tryptophan; Ts: Treponema socranskii subsp. paredis ATCC 35535; Tyr: Tyrosine; WB: Western blot;WT: Wild type.

\section{Supplementary Information}

The online version contains supplementary material available at https://doi. org/10.1186/s12934-021-01735-8.

Additional file 1: Figure S1. LC-MS profile of E. coli culture medium at $275 \mathrm{~nm}$ wavelength. Retention time of 4.64 and 6.39 min corresponds to the $p$ Cou and $t$ CA standards correspondingly. A profile from strain harboring $\mathrm{pEEK}{ }^{*}$ plasmid; $\mathbf{B}$ profile from strain harboring $T$ s tal in $\mathrm{pEEK}$ vector. $\mathbf{C}$ profile from strain harboring $T s-H 87 \mathrm{~L}$ pal in $\mathrm{pEEK}$ vector. Figure S2. Mass spectrum of the peak at $5.669 \mathrm{~min}$ in culture growth medium of EvC $\triangle$ s/r1573 strain. A positive ionization; B negative ionization. 


\section{Acknowledgements}

The authors thank Dr. Elias Englund for providing the pEEK3 and pEEK* plasmid backbones.

\section{Authors' contributions}

KK, and PL designed the study. KK performed experiments. PL supervised work in the project. KK and PL analyzed data and wrote the manuscript. All authors read and approved the final manuscript.

\section{Funding}

This work was supported by Formas (Grant No. 2016-01325), and by the NordForsk NCoE program "NordAqua" (Project Number 82845).

\section{Availability of data and materials}

The datasets used and/or analysed during the current study are available from the corresponding author on reasonable request.

\section{Declarations}

Ethics approval and consent to participate

Non applicable.

\section{Consent for publication}

Non applicable.

\section{Competing interests}

The authors declare that they have no competing interests.

Received: 17 November 2021 Accepted: 29 December 2021

Published online: 10 January 2022

\section{References}

1. Pandal N. Global markets for flavors and fragrances. BCC Research: Wellesley; 2014

2. Rao SR, Ravishankar G. Plant cell cultures: chemical factories of secondary metabolites. Biotechnol Adv. 2002;20:101-53.

3. Wendisch VF. Metabolic engineering advances and prospects for amino acid production. Metab Eng. 2020;58:17-34.

4. Yadav AN. Microbial biotechnology for bio-prospecting of microbial bioactive compounds and secondary metabolites. J Appl Biol Biotechnol. 2021;9:1-6.

5. Marienhagen J, Bott M. Metabolic engineering of microorganisms for the synthesis of plant natural products. J Biotechnol. 2013;163:166-78.

6. Chemler JA, Koffas MA. Metabolic engineering for plant natural product biosynthesis in microbes. Curr Opin Biotechnol. 2008;19:597-605.

7. Romero-Suarez D, Keasling JD, Jensen MK. Supplying plant natural products by yeast cell factories. Curr Opin Green Sustain Chem. 2021. https:// doi.org/10.1016/j.cogsc.2021.100567.

8. Hall GC, Jensen RA. Enzymological basis for growth inhibition by L-phenylalanine in the cyanobacterium Synechocystis sp. 29108. J Bacteriol. 1980;144:1034-42.

9. Herrmann KM, Weaver LM. The shikimate pathway. Annu Rev Plant Biol. 1999:50:473-503.

10. Hall G, Flick M, Gherna R, Jensen R. Biochemical diversity for biosynthesis of aromatic amino acids among the cyanobacteria. J Bacteriol. 1982;149:65-78.

11. Pfaff C, Glindemann N, Gruber J, Frentzen M, Sadre R. Chorismate pyruvate-lyase and 4-hydroxy-3-solanesylbenzoate decarboxylase are required for plastoquinone biosynthesis in the cyanobacterium Synechocystis sp. PCC6803. J Biol Chem. 2014;289:2675-86.

12. Kaneko T, Sato S, Kotani H, Tanaka A, Asamizu E, Nakamura Y, Miyajima N, Hirosawa M, Sugiura M, Sasamoto S. Sequence analysis of the genome of the unicellular cyanobacterium Synechocystis sp. strain PCC6803. II. Sequence determination of the entire genome and assignment of potential protein-coding regions. DNA Res. 1996;3:109-36.

13. Nishiyama Y, Yun C-S, Matsuda F, Sasaki T, Saito K, Tozawa Y. Expression of bacterial tyrosine ammonia-lyase creates a novel $p$-coumaric acid pathway in the biosynthesis of phenylpropanoids in Arabidopsis. Planta. 2010;232:209-18.

14. Williams JS, Thomas M, Clarke DJ. The gene st/A encodes a phenylalanine ammonia-lyase that is involved in the production of a stilbene antibiotic in Photorhabdus luminescens TT01. Microbiology. 2005;151:2543-50.

15. Zhu Y, Liao S, Ye J, Zhang H. Cloning and characterization of a novel tyrosine ammonia lyase-encoding gene involved in bagremycins biosynthesis in Streptomyces sp. Biotech Lett. 2012;34:269-74.

16. Kyndt J, Meyer T, Cusanovich M, Van Beeumen J. Characterization of a bacterial tyrosine ammonia lyase, a biosynthetic enzyme for the photoactive yellow protein. FEBS Lett. 2002;512:240-4.

17. Winkel-Shirley B. Flavonoid biosynthesis. A colorful model for genetics, biochemistry, cell biology, and biotechnology. Plant Physiol. 2001:126:485-93.

18. Moffitt MC, Louie GV, Bowman ME, Pence J, Noel JP, Moore BS. Discovery of two cyanobacterial phenylalanine ammonia lyases: kinetic and structural characterization. Biochemistry. 2007:46:1004-12.

19. Neish A. Formation of m-and p-coumaric acids by enzymatic deamination of the corresponding isomers of tyrosine. Phytochemistry. 1961;1:1-24.

20. Rosler J, Krekel F, Amrhein N, Schmid J. Maize phenylalanine ammonialyase has tyrosine ammonia-lyase activity. Plant Physiol. 1997;113:175-9.

21. Watts KT, Mijts BN, Lee PC, Manning AJ, Schmidt-Dannert C. Discovery of a substrate selectivity switch in tyrosine ammonia-lyase, a member of the aromatic amino acid lyase family. Chem Biol. 2006;13:1317-26.

22. Baedeker M, Schulz GE. Autocatalytic peptide cyclization during chain folding of histidine ammonia-lyase. Structure. 2002;10:61-7.

23. Ritter H, Schulz GE. Structural basis for the entrance into the phenylpropanoid metabolism catalyzed by phenylalanine ammonia-lyase. Plant Cell. 2004;16:3426-36

24. Jun S-Y, Sattler SA, Cortez GS, Vermerris W, Sattler SE, Kang C. Biochemical and structural analysis of substrate specificity of a phenylalanine ammonia-lyase. Plant Physiol. 2018;176:1452-68.

25. Brey LF, Włodarczyk AJ, Thøfner JFB, Burow M, Crocoll C, Nielsen I, Nielsen AJZ, Jensen PE. Metabolic engineering of Synechocystis sp. PCC 6803 for the production of aromatic amino acids and derived phenylpropanoids. Metab Eng. 2020;57:129-39.

26. Xue Y, Zhang Y, Cheng D, Daddy S, He Q. Genetically engineering Synechocystis sp. Pasteur Culture Collection 6803 for the sustainable production of the plant secondary metabolite p-coumaric acid. Proc Natl Acad Sci USA. 2014;111:9449-54

27. Gao E-B, Kyere-Yeboah K, Wu J, Oiu H. Photoautotrophic production of p-coumaric acid using genetically engineered Synechocystis sp. Pasteur Culture Collection 6803. Algal Res. 2021;54: 102180.

28. Tantong S, Nuengchamnong N, Kumphune S, Incharoensakdi A, Lindblad P, Sirikantaramas S. Synechocystis PCC 6803 cells heterologously expressing bacterial tyrosine ammonia lyase can use exogenous tyrosine for p-coumaric acid production. J Plant Biochem Biotechnol. 2018;27:118-22.

29. Ni J, Liu HY, Tao F, Wu YT, Xu P. Remodeling of the photosynthetic chain promotes direct $\mathrm{CO}_{2}$ conversion into valuable aromatic compounds. Angew Chem Int Ed Engl. 2018:57:15990-4.

30. Tiruveedula GSS, Wangikar PP. Gene essentiality, conservation index and co-evolution of genes in cyanobacteria. PLOS ONE. 2017:12: e0178565.

31. Rodrigues JS, Lindberg P. Metabolic engineering of Synechocystis sp. PCC 6803 for improved bisabolene production. Metab Eng Commun. 2021;12: e00159.

32. Dienst D, Wichmann J, Mantovani O, Rodrigues JS, Lindberg P. High density cultivation for efficient sesquiterpenoid biosynthesis in Synechocystis sp. PCC 6803. Sci Rep. 2020;10:1-16.

33. Lippi L, Bähr L, Wüstenberg A, Wilde A, Steuer R. Exploring the potential of high-density cultivation of cyanobacteria for the production of cyanophycin. Algal Res. 2018;31:363-6.

34. Röther D, Poppe L, Morlock G, Viergutz S, Rétey J. An active site homology model of phenylalanine ammonia-lyase from P. crispum. Eur J Biochem. 2002;269:3065-75.

35. Cochrane FC, Davin LB, Lewis NG. The Arabidopsis phenylalanine ammonia lyase gene family: kinetic characterization of the four PAL isoforms. Phytochemistry. 2004;65:1557-64.

36. Hemmati S. Phenylalanine ammonia-lyase through evolution: a bioinformatic approach. Trends Pharm Sci. 2015:1:10-4. 
37. Pattanaik B, Englund E, Nolte N, Lindberg P. Introduction of a green algal squalene synthase enhances squalene accumulation in a strain of Synechocystis sp. PCC 6803. Metab Eng Commun. 2020;10: e00125.

38. Englund E, Shabestary K, Hudson EP, Lindberg P. Systematic overexpression study to find target enzymes enhancing production of terpenes in Synechocystis PCC 6803, using isoprene as a model compound. Metab Eng. 2018;49:164-77.

39. Englund E, Andersen-Ranberg J, Miao R, Hamberger B, Lindberg P. Metabolic engineering of Synechocystis sp. PCC 6803 for production of the plant diterpenoid manoyl oxide. ACS Synth Biol. 2015;4:1270-8.

40. Mutalik VK, Guimaraes JC, Cambray G, Lam C, Christoffersen MJ, Mai Q-A, Tran AB, Paull M, Keasling JD, Arkin AP. Precise and reliable gene expression via standard transcription and translation initiation elements. Nat Methods. 2013;10:354-60.

41. Thiel K, Mulaku E, Dandapani H, Nagy C, Aro E-M, Kallio P. Translation efficiency of heterologous proteins is significantly affected by the genetic context of RBS sequences in engineered cyanobacterium Synechocystis sp. PCC 6803. Microb Cell Fact. 2018;17:1-12.

42. Lou C, Stanton B, Chen Y-J, Munsky B, Voigt CA. Ribozyme-based insulator parts buffer synthetic circuits from genetic context. Nat Biotechnol. 2012;30:1137-42.

43. Liu X, Miao R, Lindberg P, Lindblad P. Modular engineering for efficient photosynthetic biosynthesis of 1-butanol from $\mathrm{CO}_{2}$ in cyanobacteria. Energy Environ Sci. 2019;12:2765-77.

44. Janusz G, Pawlik A, Świderska-Burek U, Polak J, Sulej J, Jarosz-Wilkołazka A, Paszczyński A. Laccase properties, physiological functions, and evolution. Int J Mol Sci. 2020;21:966.

45. Stanier R, Cohen-Bazire G. Phototrophic prokaryotes: the cyanobacteria. Annu Rev Microbiol. 1977;31:225-74.

46. Heidorn T, Camsund D, Huang H-H, Lindberg P, Oliveira P, Stensjö K, Lindblad P. Synthetic biology in cyanobacteria: engineering and analyzing novel functions. Methods Enzymol. 2011:497:539-79.

47. Huang H-H, Camsund D, Lindblad P, Heidorn T. Design and characterization of molecular tools for a synthetic biology approach towards developing cyanobacterial biotechnology. Nucleic Acids Res. 2010;38:2577-93.

48. Elowitz MB, Leibler S. A synthetic oscillatory network of transcriptional regulators. Nature. 2000;403:335-8.

49. Ivleva NB, Golden SS. Protein extraction, fractionation, and purification from cyanobacteria. In: Rosato E, editor. Circadian rhythms. Springer: Berlin; 2007. p. 365-73.

50. Ritchie RJ. Consistent sets of spectrophotometric chlorophyll equations for acetone, methanol and ethanol solvents. Photosynth Res. 2006;89:27-41.

51. Wellburn AR. The spectral determination of chlorophylls $a$ and $b$, as well as total carotenoids, using various solvents with spectrophotometers of different resolution. J Plant Physiol. 1994;144:307-13.

52. Bennett A, Bogorad L. Complementary chromatic adaptation in a filamentous blue-green alga. J Cell Biol. 1973;58:419-35.

\section{Publisher's Note}

Springer Nature remains neutral with regard to jurisdictional claims in published maps and institutional affiliations.

Ready to submit your research? Choose BMC and benefit from:

- fast, convenient online submission

- thorough peer review by experienced researchers in your field

- rapid publication on acceptance

- support for research data, including large and complex data types

- gold Open Access which fosters wider collaboration and increased citations

- maximum visibility for your research: over $100 \mathrm{M}$ website views per year

At BMC, research is always in progress.

Learn more biomedcentral.com/submissions 